\title{
The Co-occurrence of a Substance P-like Peptide and Cholecystokinin-8 in a Fiber System of Turtle Cortex ${ }^{1}$
}

\author{
ANTON REINER, ${ }^{*, 2}$ WILLIAM D. ELDRED, $\ddagger$ MARGERY C. BEINFELD,§ AND JAMES E. KRAUSE\| \\ * Department of Anatomy and Cell Biology, University of Michigan, Ann Arbor, Michigan 48109, $\ddagger$ Department of Biology, Boston \\ University, Boston, Massachusetts, 02115, § Department of Pharmacology, St. Louis University, St. Louis, Missouri 63104, and \\ \| Department of Anatomy and Neurobiology, Washington University, St. Louis, Missouri 63110
}

\begin{abstract}
Single-label and double-label immunohistochemical techniques were used to demonstrate the coexistence of substance P-like immunoreactivity (SPLI) and cholecystokinin-8like immunoreactivity (CCK-8-LI) in an extensive fiber system within the telencephalic cortex of turtle. All SPLI-containing fibers and terminals of this system contain CCK-8-LI and vice versa. The fibers of this system course from more medial cortical regions to more lateral ones, originating either from neurons in the more medial cortices or from extracortical neurons, the axons of which ascend the medial wall of the cortex. The precise location of the neurons that give rise to this cortical projection system is uncertain, but a hypothalamic location seems most likely at present. The fibers and terminals of this system are found throughout the entire mediolateral and rostrocaudal extent of the telencephalic cortex of turtle and are largely confined to the cell body layer of the cortex. Fewer SPLI/CCK-8-LI-containing fibers are found in pyriform (olfactory) cortex than in the other cortices. Ultrastructural studies indicate that SPLI/CCK-8-LI-containing terminals make asymmetric synapses on cell bodies or their proximal dendrites. Both SPLI and CCK-8-LI are found in large dense core vesicles in these labeled terminals. Labeled terminals also contained numerous small, round, unlabeled vesicles clustered near synaptic release sites and a number of unlabeled large dense core vesicles. Quantification of the percentage of the large dense core vesicles that were labeled in SP-labeled terminals, in CCK-8-labeled terminals, and in terminals labeled for both SP and CCK-8 provided suggestive evidence that SPLI and CCK-8-LI must be contained within the same large dense core vesicles.

Radioimmunoassay indicated that the SP/CCK-8-containing system of turtle cortex contains $0.93 \pm 0.090 \mathrm{pg}$ of $\mathrm{SP} /$ $\mu \mathrm{g}$ of cortical tissue protein and $0.31 \pm 0.11 \mathrm{pg}$ of CCK-8/ $\mu \mathrm{g}$ of cortical tissue protein. The CCK-8-like material in turtle
\end{abstract}

Received August 3, 1984; Revised December 17, 1984

Accepted December 18, 1984

\footnotetext{
${ }^{1}$ We gratefully acknowledge the technical assistance of Patricia A. Lin daman, the photographic services of John Beckerman and Theresa Gonzales, and the valuable assistance of Fay Eldred, a skilled electron microscopist who served as one of the observers who counted labeled and unlabeled large dense-core vesicles. This research was supported by $\mathrm{Na}$ tional Institutes of Health Grants NS-19620 (A. R.), NS-21937 (J. E. K.) NS18335, and NS-18667, by a grant from the American Parkinson Disease Association (M. C. B.), and by National Institutes of Health Grant EY-04785 (W. D. E.).

${ }^{2}$ To whom correspondence should be addressed.
}

cortex coelutes with CCK-8-sulfate, using gradient elution high pressure liquid chromatography (HPLC). The SP-like material, although immunologically highly similar to undecapeptide SP (Reiner, A., J. E. Krause, K. T. Keyser, W. D. Eldred, and J. F. McKelvy (1984) J. Comp. Neurol. 226: 5075), does not coelute with undecapeptide SP using gradient elution HPLC. The SP-like material elutes in a single peak that is clearly distinct from those for eledoisin, physalaemin, $\beta$-neurokinin, and substance $P$ and is consistently distinct but near those for substance $K$ and kassinin.

The function of this SP/CCK-8-containing circuit in turtle cortex is presently unclear, as are the roles of the SP-like and CCK-8-like materials in this system. Both SP and CCK-8 have excitatory effects on cortical neurons in mammals, and both SP-containing perikarya and fibers and CCK-8-containing perikarya and fibers have been found in the neocortex of several mammalian groups. Since the telencephalic cortex of turtles is generally thought to be an antecedent of at least parts of mammalian neocortex, the present results raise the possibility that SP and CCK-8 may co-occur in individual cortical neurons or fibers in at least some mammals. Previous studies have shown that SP and CCK-8 co-occur in neurons of central gray and dorsal root ganglia in rats. The SP/CCK8-containing system of turtle cortex may provide a useful model system in which to study the interactions of these two peptides in influencing the responses of postsynaptic target cells.

A number of recent studies have identified specific neural systems in which a neuropeptide is present in the same neurons with a conventional neurotransmitter. For example, substance $P(S P)^{3}$ has been found in serotonergic neurons of the raphe (Chan-Palay et al., 1978; Hokfelt et al., 1978; Chan-Palay, 1979), the C-terminal octapeptide of cholecystokinin (CCK-8) has been found in dopaminergic neurons of the ventral tegmental area (Hokfelt et al., 1980a, b), a pancreatic polypeptide-like substance (apparently neuropeptide $Y$ ) has been found in adrenergic neurons of sympathetic ganglia and in catecholaminergic neurons of locus ceruleus (Hunt et al., 1981; Jacobowitz and Olschowka, 1982), and vasoactive intestinal poly-

\footnotetext{
${ }^{3}$ The abbreviations used in the text are: CCK-8, cholecystokinin-8; CCK8-LI, cholecystokinin-8-like immunoreactivity; $\mathrm{CD}$, dorsal cortex; $\mathrm{CDM}$, dorsomedial cortex; $\mathrm{CM}$, medial cortex; $\mathrm{CP}$, pyriform corlex; $\mathrm{DAB}$, diarsinoberzidine tetrahydrochloride; FITC, fluorescein isothiocyanate; HPLC, high performance liquid chromatography; LDCVs, large dense-core vesicles; PAP, peroxidase-antiperoxidase; $\mathrm{PB}$, phosphate buffer $(\mathrm{pH} 7.4)$; $\mathrm{PT}$, pallial thickening; RIA, radioimmunoassay; $S P$, substance $P$; $S P L I$, substance $P$-like immunoreactivity; TRH, thyrotropin-releasing hormone; TRITC, tetramethyl rhodamine isothiocyanate; VIP, vasoactive intestinal polypeptide.
} 
peptide (VIP) has been found in cholinergic neurons of both parasympathetic and sympathetic ganglia (Lundberg et al., 1979; Johansson and Lundberg, 1981). The seemingly common co-occurrence of neuropeptides and conventional transmitters within individual neurons has been taken to support the suggestion that, in general, the role of neuropeptides is to modulate the responses of postsynaptic target cells to primary neurotransmitters (Hoktelt et al., 1980c). This view is consistent with electrophysiological studies that have shown that peptides (e.g., SP and luteinizing hormone-releasing hormone) have synaptic actions that are slow in onset, long in duration, and often subthreshold for eliciting action potentials (Adams and Brown, 1980; Jan et al., 1980; Nicoll, 1982; Nowak and McDonald, 1982; Jan and Jan, 1983). Several recent immunohistochemical studies in mammals and birds have shown that in some systems two neuropeptides are present in the same neurons with a conventional transmitter. For example, thyrotropin-releasing hormone $(\mathrm{TRH})$ and SP have been found in serotonergic neurons of the raphe (Johansson et al., 1981), and SP and enkephalin have been found in preganglionic cholinergic terminals within the avian ciliary ganglion (Erichsen et al., 1982a). In these systems, both peptides may act to modulate the responses of the postsynaptic target cells to the primary neurotransmitters. In a number of additional neural systems, two peptides have been co-localized to individual neurons in which the conventional transmitter has not yet been identified, but in which a conventional transmitter is presumably present. For example, pancreatic polypeptide-like immunoreactivity has been found in some enkephalinergic neurons of caudal rat spinal cord (Hunt et al., 1981), pancreatic polypeptide-like immunoreactivity (apparently indicating the presence of neuropeptide $Y$ ) has been found in telencephalic somatostatinergic neurons in rats and humans (Vincent et al., 1982a, b), SP has been found in enkephalinergic neurons of many cell groups of the avian brain (Erichsen et al., 1982a), and dynorphin has been found in vasopressinergic neurons in the hypothalamic magnocellular secretory cell groups of rat (Watson et al., 1982). In some cases, the coexistence of two or more peptides in the same neurons reflects the derivation of the peptides from a common precursor molecule (i.e., a single gene product, as in the case of the co-localization of ACTH-related peptides and $\beta$-endorphin in hypothalamic neurons; Watson et al., 1978). In the case of the peptides listed above, however, the co-occurrent peptides appear to be independent gene products. Although the precise functional significance of peptide-peptide coexistence is unclear, such coexistence appears common in the nervous systems of both mammals and non-mammals. In the present paper we report our findings on the co-occurrence of SP and CCK- 8 in an extensive fiber system of turtie telencephalic cortex. These two peptides have also been recently reported to co-occur in a population of periaqueductal gray nourons (Skirboll ct al., 1982) and in some neurons of dorsal root ganglion in the rat (Dalsgaard et al., 1982).

\section{Material and Methods}

The subjects of the present study were adult mud turties (Kinosternum subrubrum), painted turtles (Chrysemys picta), and red-eared turtles (Pseudemys scripta). Using standard single-label immunohistochemical techniques, the coexistence of SP and CCK-8 in fibers of turtle cortex was implied by the similar individual staining patterns for these two peptides. The coexistence of SP and CCK-8 in turtle cortex was confirmed using a light microscopic immunofluorescence double-label procedure used previously by Erichsen et al. (1982a) and several other authors (Grimmelikhuijzen, 1983; Oertel et al., 1983; Wessendorf and Elde, 1985). The SP. and CCK-8containing fibers were subsequently examined individually using single-label electron microscopic immunohistochemical techniques in order to determine the ultrastructural localization of these peptides. Finally, high performance liquid chromatography (HPLC) was used to analyze the chemical nature of the immunoreactive substances that had been detected in turtie cortex by the immunohistochemical studies, and radioimmunoassay (RIA) was used to measure the amounts of these substances in turtle cortex.

\section{Light microscopic techniques}

Turtles were anesthetized deeply with ketamine or sodium pentobarbitol and were perfused through the heart with $6 \%$ dextran in $0.1 \mathrm{M}$ phosphate buffer, pH 7.4 (PB), followed by a solution of $4 \%$ paraformaldehyde in $\mathrm{PB}$. The brains were then dissected free from the skull, embedded in a thin coat of gelatin-albumin, and immersed in 30\% sucrose-fixative for 2 days. Brains were then sectioned frozen at $35 \mu \mathrm{m}$ on a sliding microtome. For light microscopic studies, both single-label and double-label immunohistochemical techniques were used. In single-label studies, either the indirect immunofluorescence procedure (Weller and Coons, 1954; Coons, 1958) or the peroxidase-antiperoxidase (PAP) procedure (Sternberger, 1979) was used. The double-label immunofluorescence procedure that was used will be referred to as the simultaneous immunofluorescence procedure and is described in greater detail below.

For single-label studies, sections were washed three times in PB and incubated either in a C-terminus-specific monoclonal antibody against SP raised in tissue culture from rat spleen-mouse myeloma (obtained from Accurate Chemical and Scientific Corp.) or in an antiserum raised in rabbit directed against the C-terminus octapeptide of cholecystokinin (R5). Details of the production, characterization, and specificity of these antisera have been described previously (Cuello et al., 1979; Beinfeld et al., 1981). In a previous study (Reiner et al., 1984), we found that the monoclonal antibody against SP yields the same immunohistochemical staining pattern in turtle brain as two other antisera directed against the C-terminus of SP, one of which (GPP7) was used in the present RIA study (see below), as well as in a previous RIA study of the turtle brain (Reiner et al., 1984). The monoclonal antibody against SP was used throughout the present immunohistochemical studies to achieve uniformity with the double-label studies, which called for the use of the rat monoclonal antibody in conjunction with the rabbit antiCCK-8 antiserum. Tissue incubations were carried out for 12 to $60 \mathrm{hr}$ using a primary antiserum or antibody dilution of 1:1000. All antisera for light microscopic studies were diluted with PB containing $0.3 \%$ Triton X-100. Following the incubation in primary antiserum, tissue was washed three times in PB and then processed according to either the indirect immunofluorescence procedure or the PAP procedure. Details of our techniques have been described previously (Korte et al., 1980; Reiner et al., 1982, 1983). In brief, for the immunofluorescence technique tissue was incubated in a secondary IgG conjugated to fluorescein isothiocyanate (FITC) (Miles Biochemicals) at a dilution of 1:50 for $1 \mathrm{hr}$ at room temperature. Tissue processed with the monoclonal antibody was incubated in a secondary antiserum raised in rabbit directed against rat IgG. Tissue processed with the anti-CCK- 8 antiserum was incubated in a secondary antiserum raised in goat directed against rabbit lgG. Following the incubations, sections were washed three times in PB, mounted on gelatin-coated slides, and coverslipped in a 9:1 solution of glycerol and $0.05 \mathrm{M}$ carbonate buffer ( $\mathrm{pH} 9.0$ ). Sections were examined with a Leitz Orthoplan microscope using a Ploem epi-illumination fluorescence microscopy system. For the PAP method, following incubation in the primary antiserum or antibody, sections were incubated in an unlabeled secondary antiserum (Miles Biochemicals) at a $1: 50$ dilution for $1 \mathrm{hr}$ at room temperature (rabbit anti-rat IgG for SP processing; goat anti-rabbit IgG for CCK-8 processing). Following three washes in PB, sections incubated initially in the SP antibody were incubated in PAP (antiperoxidase raised in rat) for $1 \mathrm{hr}$ at room temperature at a dilution of $1: 200$. Sections reacted with the anti-CCK8 antiserum were similarly incubated in PAP (antiperoxidase raised in rabbit). Sections were then washed three times in $\mathrm{PB}$ and reacted in a solution of diaminobenzidine tetrahydrochloride $(\mathrm{DAB})$ and $\mathrm{H}_{2} \mathrm{O}_{2}(100 \mathrm{mg}$ of $\mathrm{DAB} / 100$ $\mathrm{ml}$ of $0.1 \mathrm{M}$ cacodylate buffer $\left.(\mathrm{pH} 7.2) / 0.5 \% \mathrm{H}_{2} \mathrm{O}_{2}\right)$ to demonstrate the location of the immunologically bound peroxidase. Sections were then washed, mounted on subbed slides, and coverslipped with Permount. Specificity of immunoreactivity was determined by preabsorbing the primary antiserum or antibody with a $10 \mu \mathrm{M}$ concentration of the synthetic antigen.

For the simultaneous immunofluorescence double-label procedure, tissue was processed simultaneously for the presence of the two separatc tissuc antigens by using the anti-SP monoclonal antibody and the anti-CCK. 8 primary antiserum (which do not cross-react with each other's target antigen) and two distinct secondary antisera, one of which was specific for the ral anti-SP monoclonal antibody and the other of which was specific for the rabbit anti-CCK-8 antiserum. Each secondary antiserum was raised in goat and was conjugated to a distinct fluorophore (FITC in the case of the anti-rat IgG secondary antiserum and tetramethyl rhodamine isothiocyanate (TRITC) in the case of the anti-rabbit lgG secondary antiserum). Other commonly used double-label procedures involve either successively and separately staining the same section for different antigens using the immunofluorescence procedure (e.g., the elution technique of Tramu et al., 1978) or staining adjacent thin sections for two different antigens (Watson et al., 1982). 
Although such other techniques have been used successfully to demonstrate peptide-peptide or peptide-transmitter co-occurrence, they are most applicable to the identification of co-occurrence in perikarya that contain high peptide or transmitter levels. The simultaneous immunofluorescence technique, in contrast, can be readily used to demonstrate peptide-peptide or peptide-transmitter co-localization in all perikarya, fibers, and terminals that contain immunohistochemically detectable amounts of the peptides under investigation. With the simultaneous immunofluorescence procedure, tissue is labeled simultaneously for the presence of two different antigens. The two antigens can be separately localized by fluorescence microscopy by successively viewing the tissue using the different excitation/emission filters appropriate for the fluorophores used. The rapidity with which the labeling for two antigens can be successively examined in tissue stained with the simultaneous immunofluorescence procedure makes it possible to unequiv ocally localize the two antigens to the same axons and terminals. This characteristic of the simultaneous immunofluorescence procedure was essential for the present study.

For the simultaneous immunofluorescence procedure, tissue incubations were carried out in a primary antisera "cocktail," containing both anti-SP antibody and anti-CCK.8 antiserum at 1:1000 dilutions. After three PB washes, the tissue was subsequently incubated in a secondary antisera cocktail consisting of an anti-rabbit lgG antiserum (raised in goat) conjugated to TRITC and anti-rat lgG antiserum (raised in goat) conjugated to FITC, with each at a 1:50 dilution. Tissue was then washed, mounted on slides, coverslipped, and examined with fluorescence microscopy as described above.

\section{Electron microscopic studies}

Turtles were perfused transcardially with $6 \%$ dextran in $\mathrm{PB}$ followed by $4 \%$ paraformaldehyde and $0.2 \%$ glutaraldehyde in $\mathrm{PB}$. The brains were then removed and postfixed for 1 to $2 \mathrm{hr}$ in the same fixative, followed by overnight fixation in $4 \%$ paraformaldehyde in phosphate buffer $(\mathrm{pH} 10.4)$. Tissue was then cryoprotected using a series of glucose-glycerin-PB washes of increas ing sucrose-glycerin concentration (with a terminal concentration of $20 \%$ sucrose-10\% glycerin). Tissue was then sectioned frozen on a sliding microtome at $70 \mu \mathrm{m}$ and treated with $1 \%$ sodium borohydride in PB for 30 min. The sections were subsequently processed according to the PAP technique (but without the addition of Triton $X-100$ to any of the antisera), after which the tissue was osmicated, rapidly dehydrated with a graded series of acetone washes, and embedded in Epon. The Epon-embedded sections were examined in the light microscope to locate the labeled cortica area of interest. These regions were then cut out of the Epon, glued to a carrier block, and sectioned (silver-gold) with a diamond knife and examined with a JEOL electron microscope. This procedure for electron microscopic immunohistochemistry readily provides penetration of immunochemicals and reagents for a depth of 200 to $300 \mu \mathrm{rr}$, which is considerably grealer lhar the section thickness used in the present study. The rationale behind the different steps in this procedure has been described in greater detail (Eldred et al., 1983).

\section{Biochemical studies}

$S P$. As part of a larger study on the distribution and regional content of $\mathrm{SP}$ in the turtle brain (Reiner et al., 1984), the brains of six turtles were dissected into 10 discrete regions and, using RIA, the amount of SP in these regions was determined. Aliquots of the tissue extract from the cortica samples were subjected to HPLC for the present study. In the steps preceding HPLC, the cortical tissue was dissected from the brain, weighed homogenized, and extracted in $2.0 \mathrm{M}$ acetic acid containing $2.5 \% \beta$-mercaptoethanol. Tissue samples were acid extracted two times and the supernatants were combined, lyophilized, and reconstituted in $0.1 \%$ triffuoroacetic acid. These reconstituted samples were subjected to HPLC on a Brownlee C-8 column using a Waters Associates instrument as described previously (Krause et al., 1984). Peptides were eluted using a 1 to $30 \%$ exponential gradient ( $50 \mathrm{~min}$ ) of acetonitrile in $0.1 \mathrm{M}$ sodium phosphate $(\mathrm{pH} 2.1)$. Fractions were collected and aliquots were directly subjected to RIA using an anti-SP antiserum (GPP7, kindly provided by Drs. J. Kessler and I. Black, Cornell Medical School) at a 1:240,000 dilution. The GPP7 antiserum shows no detectable binding of CCK. 8 in this RIA. In a previous study we have shown that both GPP7 and the monoclonal antibody against SP yield identica immunohistochemical staining patterns in the telencephalon of turtles and provide similar RIA measurements for the amounts of SP in the various regions of the turtle nervous system (Reiner et al., 1984). The chromatographic migration of the SP like material of turtlo cortex was compared to tho migration of synthetic undecapeptide SP in this HPLC system. This system, provides base line separation of related tachykinins such as SP, eledoisin physalaemin, kassinin, and substance $\mathrm{K}$

SP-like immunoreactivity (SPLI) is present in fibers of two layers of turtle cortex, the cellular layer and the superficial one fourth of the molecular layer (Reiner et al., 1984). The fibers of the molecular layer containing SPLI are largely restricted to the medial and dorsomedial cortices. Previous RIA determinations for the entire mediolateral extent of the cortex (excluding the pyriform cortex) found that the cortex contained $212 \mathrm{pg}$ of SP/mg of wet weight tissue. This RIA value combines the levels of SP found in both layers of turtle cortex. In the present study it was of interest to determine the amount of SP found in the fibers of only the cellular layer of cortex. To determine this, two red-eared turtles were decapitated, and the rostral dorsa cortex was dissected on ice from the telencephalon. Since the rostral dorsa cortex does not contain the SP-containing fiber system of the molecular layer, it was thought that the concentration of SP in the rostral dorsal cortex would provide a valid indicator of the cortical concentration of the SP found in the fibers of the cellular layer. The RIA determinations were carried out as described previously (Krause et al., 1984; Reiner et al., 1984).

$\mathrm{CCK}-8$. The entire mediolateral extent of the cortex (excluding the pyriform cortex) was dissected free on ice from the telencephalon of three turtles (different from those used for the SP HPLC described above). Two mud turtles ( $K$. subrubrum) and one red-eared turtle were used. The tissue was boiled in water and sonicated in ice cold $0.1 \mathrm{~N} \mathrm{HCl}$, and an aliquot was removed for Lowry protein assay (L owry et al., 1951). After the tissue extract was clarified by centrifugation, an aliquot of the supernatant was removed for RIA and neutralized with an equal volume of $0.1 \mathrm{~N} \mathrm{NaOH}$. The RIA procedure used ${ }^{125}$-gastrin, with CCK-8-sultate as the standard. The RIA procedure used has been described in greater detail previously (Beinfeld et al., 1981). For HPLC, supernatants were combined, clarified by centrifugation, and injected onto an Altech column $(0.46 \times 2.5 \mathrm{~cm})$ run in a linear gradient of 20 to $60 \%$ acetonitrile in the presence of $0.09 \%$ trifluoroacetic acid over $40 \mathrm{~min}$. One-minute fractions were collected at a flow rate of $1 \mathrm{ml} / \mathrm{min}$. The $\mathrm{HPLC}$ fractions were dried in a Savant vacuum centrifuge and resuspended in water; then, an aliquot was removed for CCK-8 RIA. Standards were detected optically and with CCK-8 RIA. This column separates most major CCK peptides (CCK-8-sulfate, CCK-8-desulfate, CCK-4, and CCK-33) and gastrin peptides (gastrin 17-I and gastrin 17-11) (Beinfeld, 1981; Beinfeld et al., 1983).

\section{Results}

Light microscopic studies. The roof of the telencephalon in turtles has been subdivided into several discrete cortical regions (Johnston 1915: Riss et al., 1969). From medial to lateral these regions are: (1) the medial cortex (CM), (2) the dorsomedial cortex (CDM), (3) the dorsal cortex $(C D)$, and the pyriform cortex $(C P)$. In addition, the pallial thickening $(P T)$, a lateral noncortical externsion of the $C D$, car also be included as a portion of the cortical formation (see Fig. 1). The rhinal sulcus separates the CD and PT from the CP. The CM, CDM, and CD lie superficial to the lateral ventricle. This supraventricular portion of the cortex consists of three layers: a broad superficial molecular layer, a narrow cellular layer, and a narrow subcellular layer. The subcellular layer broadens laterally as the CD grades into the PT. The CP consists of a superficial molecular layer and a deeper cellular layer. These four cortical regions (CM, CDM, CD-PT, and $\mathrm{CP}$ ) span the entire rostrocaudal extent of the telencephalon caudal to the olfactory bulb. In telencephalic tissue processed immunohistochemically for SP, a tangled collection of labeled fibers and terminals was observed in the entire rostrocaudal extent of the cortex medial to the rhinal fissure, spanning the CM, CDM, CD, and PT. This band of SPLI-containing fibers was almost exclusively restricted to the cellular layer of the cortex (Fig. 2). The band of fibers consisted of numerous individual, sinuous SPLI-containing fibers, each containing many en passant terminals (approximately 2 to $5 \mu \mathrm{m}$ in diameter) that could be seen to contact neuronal cell bodies of the cortical perikaryal layer (Figs. 2 and 3). An identical immunohistochemical staining pattern was observed in turtle cortex when the GPP7 antiserum was used to stain turtle telencephalon (Reiner et al., 1984). Sections through the turtle telencephalon processed for CCK-8 revealed a pattern of fiber staining in the portion of the cortex medial to the rhinal sulcus identical to that seen following processing with the monoclonal anti-SP antibody (Fig. 2). The CCK-8-like immunoreactivity (CCK-8-LI)-containing fibers in cor- 

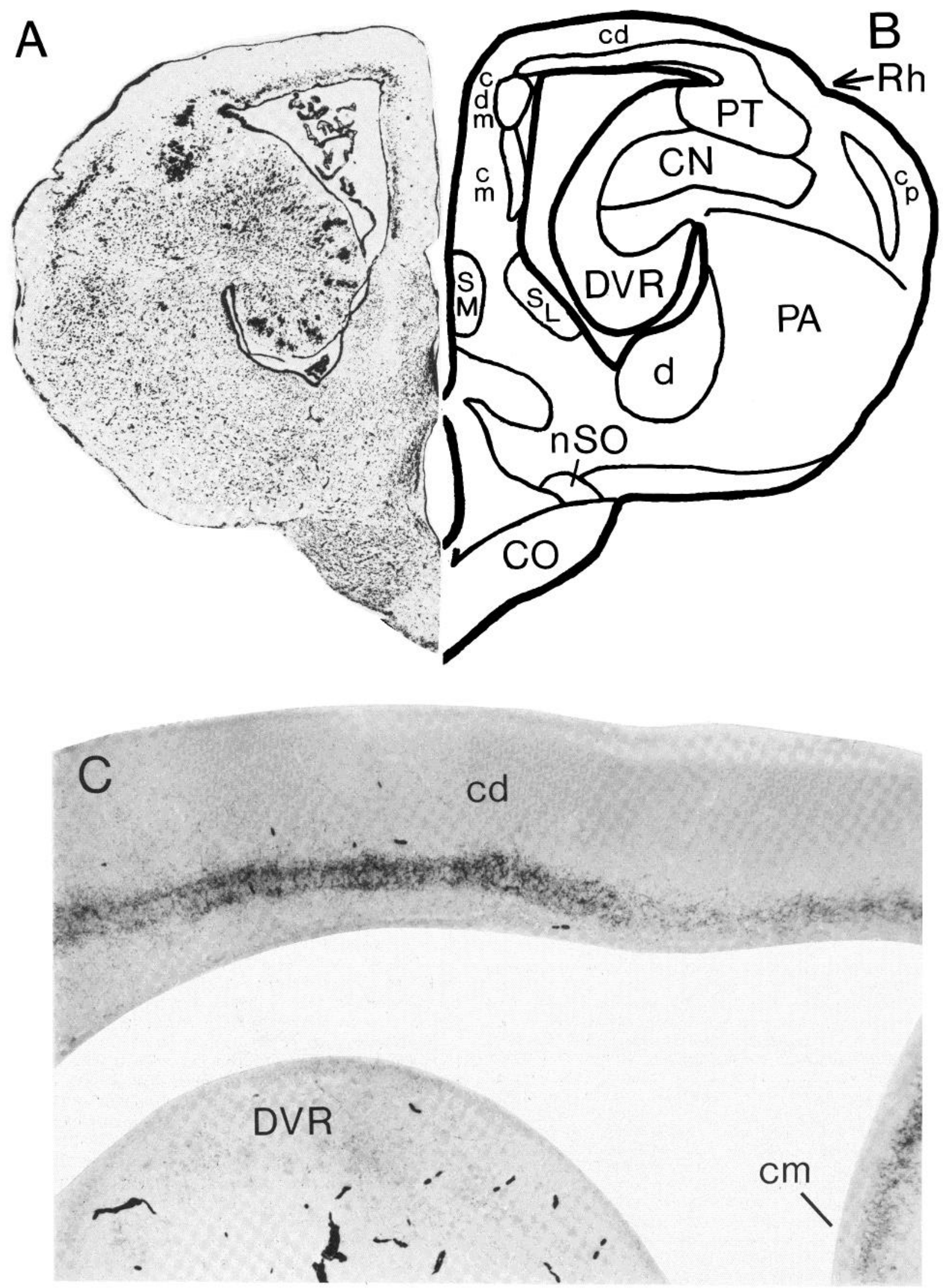

Figure 1. Low power, high contrast photomicrograph of a Nissl-stained transverse section through the telencephalon of a turtle $(A)$ and a matching line drawing of this section $(B)$ showing the boundaries of the major cell groups. The roof of the turtle telencephalon consists of four distinct cell groups: CM, $\mathrm{CDM}, \mathrm{CD}$, and $\mathrm{CP}$. The rhinal sulcus $(R h)$ marks the boundary between $\mathrm{CD}$ and $\mathrm{CP}$. CD has a lateral noncortical extension termed PT. In $C$ a photomicrograph of the SPLI-containing fibers of the cellular layers of CD and CDM is shown. CN, core nucleus of the dorsal ventricular ridge; $C O$, optic chiasm; DVR, dorsal ventricular ridge; $d$, area $d$ of Riss et al. (1969); $n S O$, supraoptic nucleus; $S L$, lateral septal nucleus; $S M$, medial septal nucleus. 

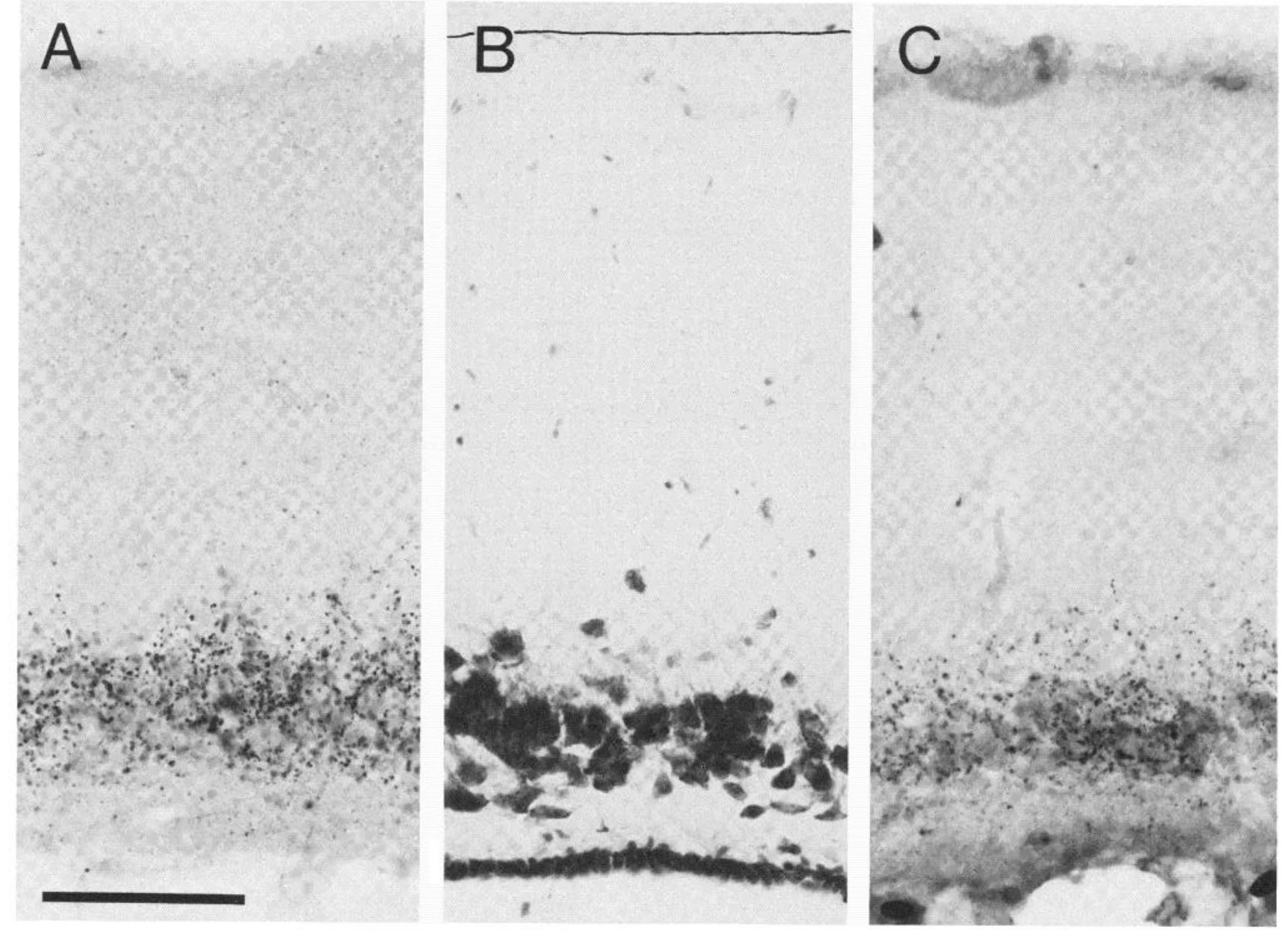

Figure 2. Photomicrographs of transverse sections through CD labeled according to the PAP procedure for SP $(A)$, stained with cresyl violet for Nissl substance $(B)$, and labeled according to the PAP procedure for CCK-8 $(C)$. Note that a dense collection of fibers and terminals is present in the cellular layer of cortex both in tissue stained for SP $(A)$ and in tissue stained for CCK-8 (C). The line in $B$ highlights the superficial edge of the cortex. Scale bar $=$ $100 \mu \mathrm{m}$.

tex were also largely restricted to the cellular layer of the cortex, spanning CM, CDM, and CD/PT throughout the rostrocaudal extent of the turtle cortex (Fig. 4). The morphology of these CCK-8-LIcontaining fibers and their density were identical to those observed with the anti-SP antibody. Staining of the cortical fibers with the anti$\mathrm{SP}$ antibody could be blocked by $10 \mu \mathrm{M}$ synthetic SP, and staining of the fibers with the anti-CCK- 8 antiserum could be blocked with $10 \mu \mathrm{M}$ synthetic CCK-8. Staining of the cortical fibers with the antiCCK-8 antiserum, however, was not affected by $10 \mu \mathrm{M}$ synthetic SP. Since the anti-SP antibody is a monoclonal antibody specific for the C-terminus of SP, it seemed extremely unlikely that synthetic CCK- 8 could block cortical staining with the anti-SP antibody. Consequently, cross-blocking experiments using the anti-SP antibody and synthetic CCK-8 were not performed.

The seeming congruence between the SPLI-containing fibers and the CCK-8-LI-containing fibers of turtle cortex prompted double-label studies to determine if, in fact, the same fibers contained both SPLI and CCK-8-LI. Successive viewing of TRITC labeling and FITC labeling in tissue processed according to the simultaneous immunofluorescence procedure revealed that, apparently, all labeled fibers of the cellular layer of turtle cortex medial to the rhinal sulcus contained both SPLI and CCK-8-LI (Figs. 5 and 6). These SPLI/CCK8-LI-containing fibers were present throughout the entire expanse of the cortical area in which both SPLI-containing and CCK-8-LI-containing fibers were observed in single-label studies. In addition, a few SPLI//CCK-8-LI-containing fibers were observed in the cellular layer of the CP at all topographic levels of the CP, and SPLI/CCK-8-
LI-containing fibers were present in low density in the molecular layer, slightly superficial to the cellular layers of $\mathrm{CM}, \mathrm{CDM}$, and $\mathrm{CD}$ / PT. On the order of a thousand individual labeled terminals were examined throughout the entire extent of the cortex medial to the rhinal fissure, and in all cases each terminal was labeled for both SPLI and CCK-8-LI. However, the relative intensity of the labeling for SPLI compared to that for CCK-8-LI did seemingly vary slightly from individual terminal to individual terminal. In general, these labeled terminals, in both single-label and double-label studies, were somewhat more heavily labeled for SP than for CCK-8.

All SPLI-containing fibers of turtle cortex, however, were not restricted to the cellular layer and its immediate vicinity. Diffuse SPLI (which was presumed to represent the presence of fine SPLIcontaining fibers) was observed in the superficial fourth of the molecular layer of the CM and CDM in both single-label and doublelabel studies. Fibers containing CCK-8-LI were not observed in this layer of the cortex. Thus, all immunohistochemically detectible CCK8-LI-containing fibers of cortex appear to contain SPLI and are restricted to the cellular layer. In contrast, in telencephalic regions outside the cortex, CCK-8-LI-containing fibers that did not contain SPLI were abundant. In general, the SPLI and CCK-8-LI labeling patterns in noncortical regions of the telencephalon were disjunctive (Fig. 6) except for a few pericellular terminals in the lateral septum and a few scattered fibers in the dorsal ventricular ridge that contained both SPLI and CCK-8-LI.

The source of the SPLI/CCK-8-LI-containing fibers in turtle cortex was examined in a knife cut experiment. Desan (1981) had previously 
Figure 3. Photomicrographs of $\mathrm{CM}(A)$ and $\operatorname{CDM}(B)$ in tissue labeled for SP according to the PAP procedure. The entire depth of cortex is illustrated in $A$, and only the deeper half of cortex is illustrated in $B$. Neurons containing SPLI are observed in the molecular, cellular, and subcellular layers of cortex in $A$ and in the subcellular layer in $B$. The labeled neuron in $B$ can be seen to give rise to a fiber (apparently a dendrite) that ramifies within the cellular layer of cortex. The dendrite of this neuron was observed to give rise to a thin axon (not evident in the photomicrograph) that could be traced into but not beyond the cell body layer. In addition to the SPLI-containing fibers of the cortical layer and the SPLI-containing cortical neurons, $A$ also illustrates the SPLI-containing fibers present in the superficial fourth of the molecular layer of cortex. Superficial and medial are to the left in both photomicrographs, and dorsal is toward the top. Scale bars: $A=$ $100 \mu \mathrm{m} ; B=50 \mu \mathrm{m}$.
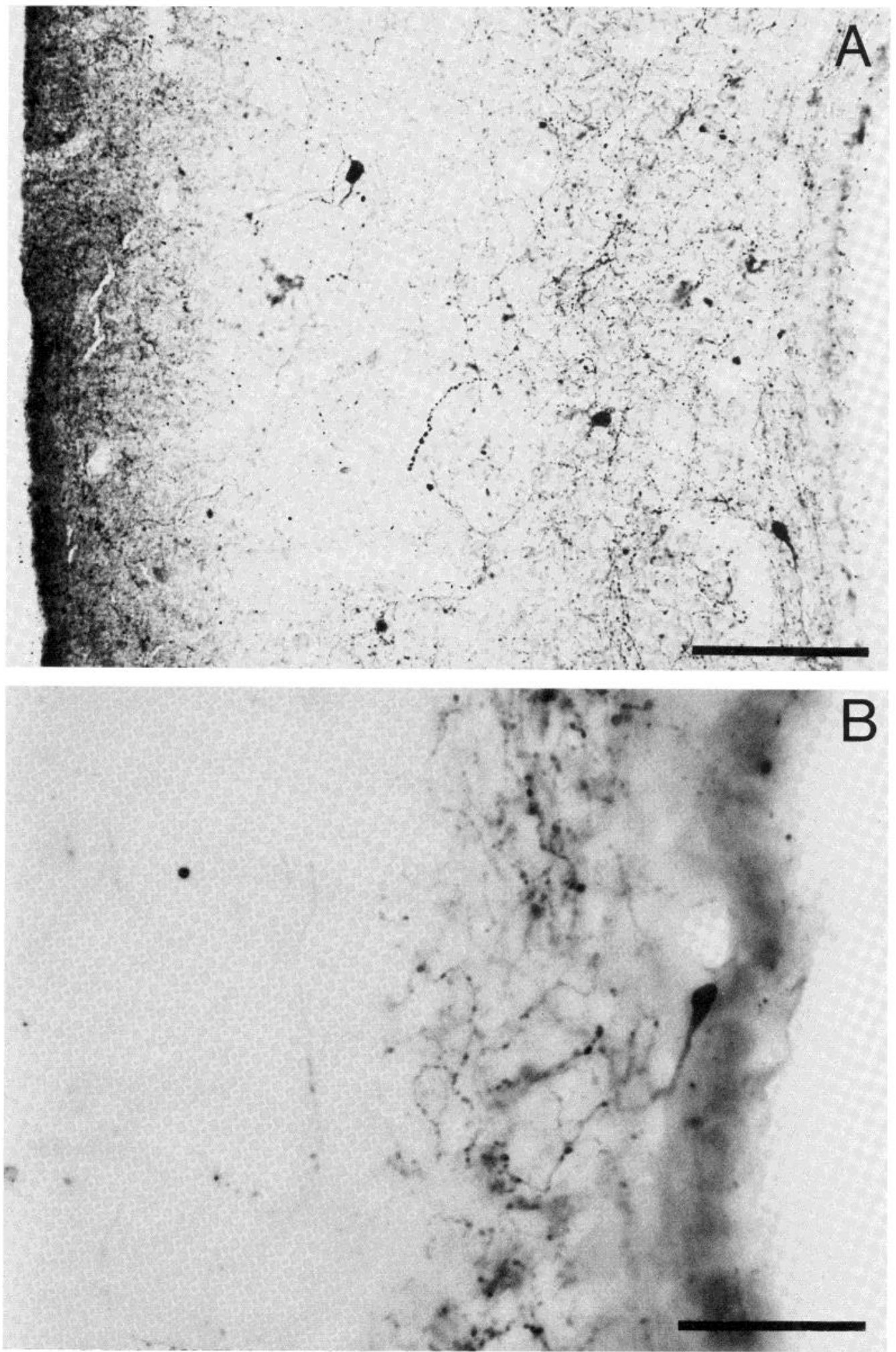

suggested that more medial portions of turtle cortex (including CDM and $\mathrm{CM}$ ) give rise to a projection system that has terminals in the cellular layer throughout the entire cortex. In the present study, numerous heavily labeled SPLI-containing neurons were observed in $\mathrm{CM}$ and CDM. In some cases, the processes of these neurons could be observed to ramify in the cellular layer (Fig. 3). These results suggested that SPLI-containing cortical neurons might give rise to intrinsic SPLI-containing cortical fibers. CCK-8-LI-containing neurons were, however, rarely observed in CM and CDM. Further- more, the co-occurrence of SPLI and CCK-8-LI in cortical neurons could not be demonstrated, possibly due to the rareness and caseto-case variability in labeling of CCK-8-LI-containing neurons. Recently, Desan (1984) and Bruce and Butler (1984) have shown that the neurons in the lateral and supramamillary regions of the hypothalamus in turtles and lizards project to the cortex. The route of this projection into the cortex is uncertain, but it seems likely that this projection courses via the medial forebrain bundle and enters the cortex via the medial wall of the telencephalon. Reiner et al. (1984) 


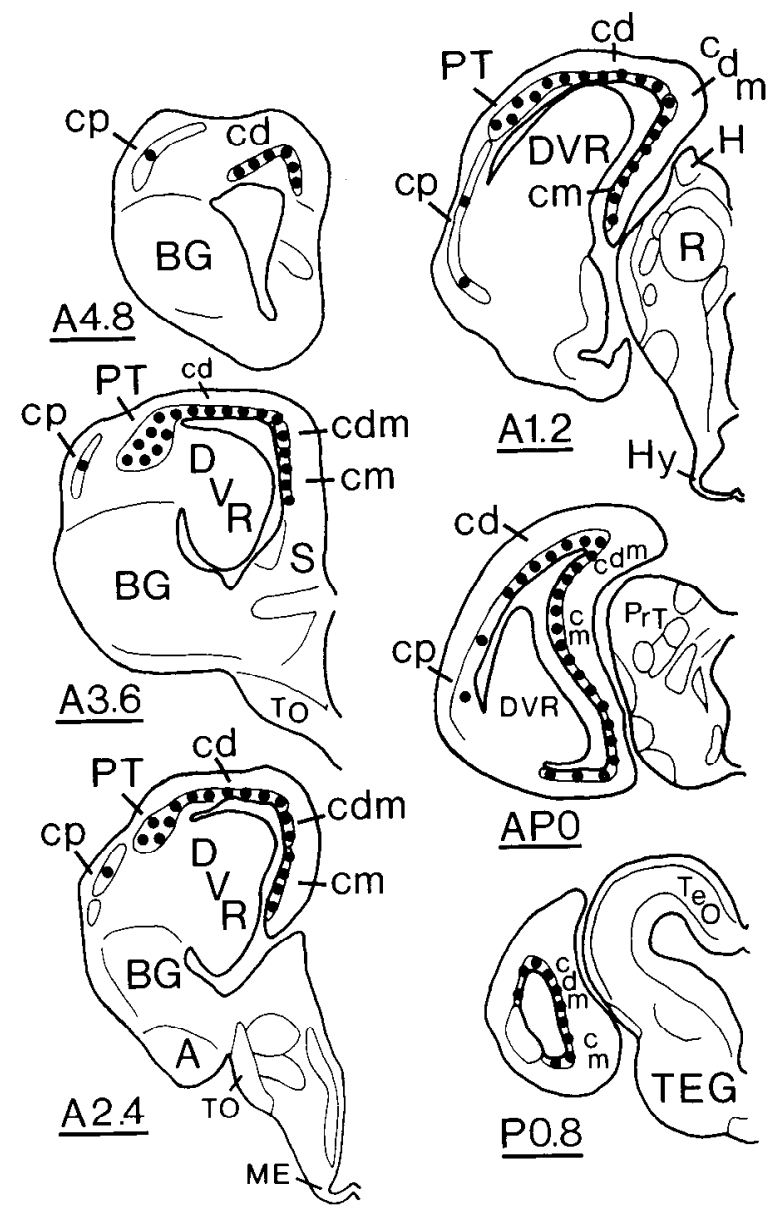

Figure 4. Line drawings of transverse sections through the rostrocaudal extent of the turtle telencephalon $(A$ to $F$ ). Solid circles indicate the location, extent, and relative density of SPL/CCK-8-LI-containing fibers and terminals in the telencephalon of turtle. Medial is to the right in all of the drawings. The numbers to the lower left of each section identify the level of that section in terms of the stereotaxic atlas of the turtle brain of Powers and Reiner (1980). $A$, amygdala; $B G$, basal ganglia; $D V R$, dorsal ventricular ridge; $H$, habenula; $H y$, neurohypophysis; $M E$, median emincnce; $P r T$, pretectum; $R$, nucleus rotundus; $S$, septum; TEG, tegmentum; TeO, optic tectum; TO, optic tract.

and A. Reiner and M. C. Beinfeld (submitted for publication) have observed that these regions of the hypothalamus are rich in SPLIcontaining and CCK-8-LI-containing neurons. Using the simultaneous immunofluorescence procedure, we have observed that SPLI and CCK-8-LI coexist in many neurons in the lateral and supramamillary portions of the turtle hypothalamus (Fig. 7). In order to examine the possibility that the SPLI/CCK-8-LI-containing fibers course from more medial cortical regions to lateral ones (originating either from the medial portions of the cortex or from neurons whose axons enter the cortex via the medial wall), cortical knife cuts were made in several turtles using stereotaxic procedures (Powers and Reiner, 1980; Brauth et al., 1983). In one turtle, the knife cut separated more medial cortical regions ( $\mathrm{CM}$ and $\mathrm{CDM}$ ) from more lateral cortical regions (CD/PT) through a large portion of one telencephalic hemisphere. In this turtle, SPLI-containing and CCK-8-LI-containing fibers were considerably reduced or eliminated, depending on the rostrocaudal level examined, lateral (and presumably distal) to the knife cut (Fig. 8). Fiber staining medial to the knife cut was somewhat attenuated. The basis of the effect on medial cortical regions was unclear but may have involved either retrograde axonal degeneration or necrosis due to direct damage to $\mathrm{CM}$ and CDM by the knife cut. Since neurons of the lateral and supramamillary hypothalamus project to the cortex and since SPLI and CCK-8-LI coexist in neurons in these hypothalamic regions, it appears likely that the SPLI/CCK-
8-LI-containing cortical fibers observed in the present study are of hypothalamic origin.

In light of the coexistence of SPLI and CCK-8-LI in apparently all labeled fibers of the cellular layer of supraventricular cortex, we examined the possibility that the double labeling was spurious. Spurious double labeling could occur under several circumstances: (1) if the anti-SP primary antibody cross-reacts with CCK-8 or if the anti-CCK-8 primary antiserum cross-reacts with $\mathrm{SP},(2)$ if the anti-rat IgG secondary antiserum binds to either the CCK-8 antiserum or the anti-rabbit lgG secondary antiserum, or if the anti-rabbit lgG secondary antiserum binds to either the anti-SP antibody or to the anti-rat IgG sccondary antiscrum, or (3) if some previously unrecognized neuropeptide, whose amino acid sequence contains antigenic determinants recognized by both the anti-SP antibody and by the antiCCK-8 antiserum, is present in turtle cortex.

It seemed unlikely that either the anti-SP antibody or the anti-CCK8 antiserum cross-reacted with CCK-8 or SP, respectively. The antiSP antibody and the anti-CCK- 8 antiserum are specific for the C-terminus of SP and the C-terminus of CCK- 8 , respectively (Cuello et al., 1979; Beinfeld et al., 1981). No common amino acid sequences are shared by SP and CCK-8. Consistent with the reported specificity of the anti-CCK-8 antiserum, $10 \mu \mathrm{M}$ SP did not block cortical staining with the anti-CCK-8 antiserum, whereas this antiserum could be completely blocked with $10 \mu \mathrm{M}$ synthetic CCK-8. As noted above, similar cross-blocking studies were not carried out with the anti-SP antibody due to the reported high specificity of this antibody for the C-terminus of SP. It also seemed unlikely that the anti-rat lgG secondary antiserum bound to the rabbit anti-CCK-8 antibodies or that the anti-rabbit IgG secondary antiserum bound to the rat anti-SP antibody. It further seemed unlikely that the two secondary antisera bound to each other, since both were raised in goat. If binding by either secondary antiserum crossed over to the other primary or secondary antisera, then all neurons and fibers labeled for SP also should have been labeled for CCK-8 and vice versa. In fact, numerous SPLI-containing neurons and fibers were observed in turtle telencephalon that did not contain CCK-8-LI (most strikingly in the basal ganglia; see Fig. 6), and vice versa. In addition, in both the present study and a previous study using the simultaneous immunofluorescence procedure (Erichsen et al., 1982a), we found that incubation of the tissue in only one of the two primary antisera followed by incubation in both secondary antisera resulted in staining only for the one substance against which the non-omitted primary antiserum was directed. In the present study, we found that after omission of the anti-SP antibody from the primary antiserum "cocktail" and incubation in both secondary anlisera, the fibers of the cortical cellular layer were stained for CCK -8 but not SP. Similarly, omission of the anti-CCK- 8 antiserum from the primary antiserum cocktail followed by incubation in both secondary antisera resulted in cortical staining for SP but not CCK-8. Finally, the possibility that the SP-like antigen and the CCK-8-like antigen are present as portions of a novel neuropeptide found in turtle cortex was explored, as described below, in biochemical studies. In brief, HPLC analysis indicated that both a distinct SP-like substance and a distinct CCK8 -like substance are present in turtle cortex and that these substances are highly similar or identical to the counterpart peptides that have been extracted from mammalian nervous tissue.

Electron microscopic studies. The ultrastructural distribution of SPLI was indistinguishable from that of CCK-8-LI. The following general description pertains to both. Labeled boutons were located at low magnification by their increased electron density and were readily distinguishable from unlabled boutons (Figs. 9 and 10). The individual labeled boutons that were observed ranged in size from 2 to $5 \mu \mathrm{m}$ in diameter. These labeled boutons were observed to contact and synapse on cell bodies or their primary dendrites. Numerous unlabeled terminals were also seen to synapse on these cell bodies and dendrites. Labeled terminals contained numerous small $(620 \mathrm{~nm})$, unlabeled, round clear vesicles, which were clustered in large numbers near presynaptic membrane. In regions of 

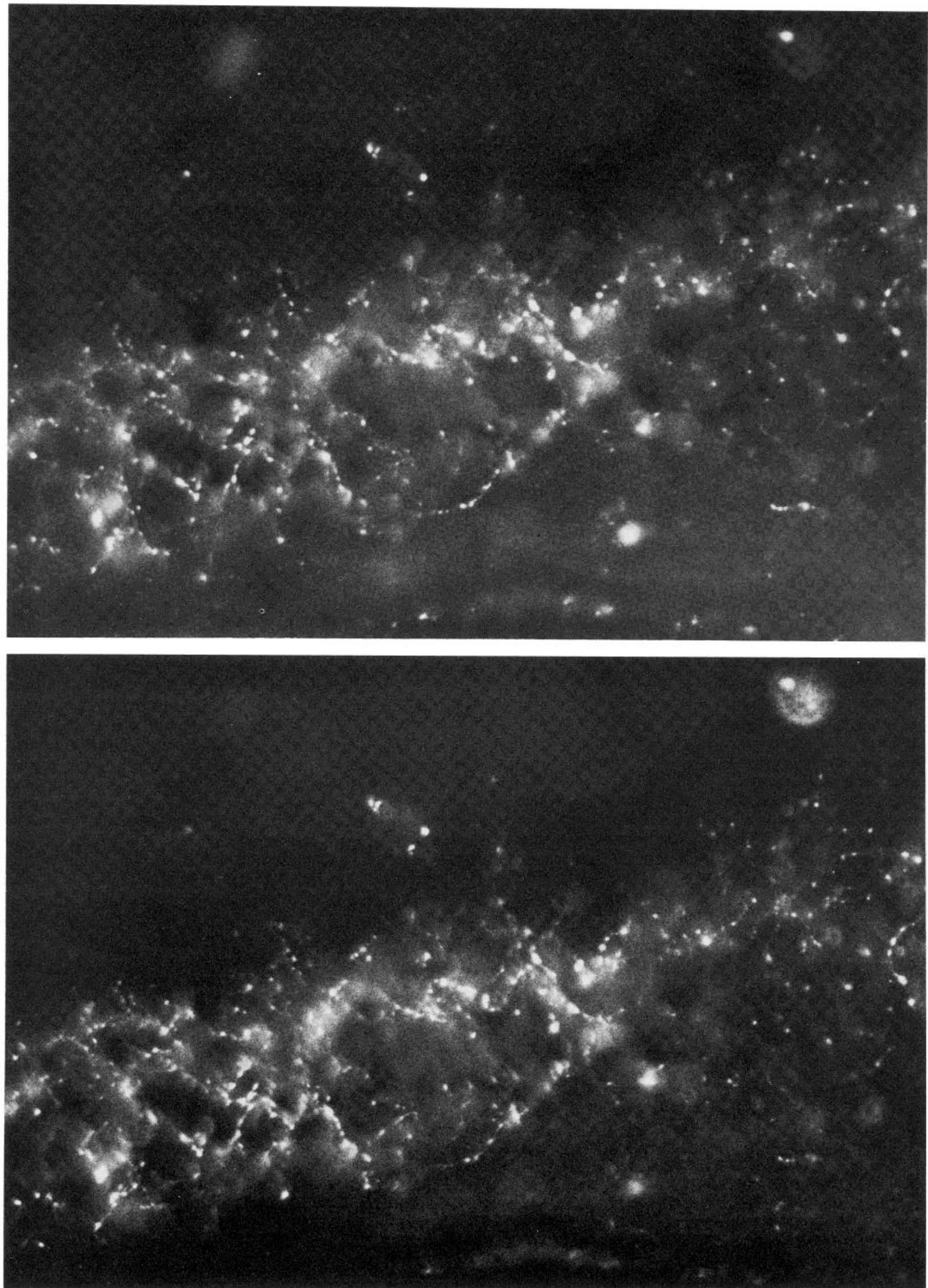

Figure 5. A pair of photomicrographs of the same field of view of CD in a transverse section that had been processed for the presence of both SP and CCK-8 according to the simultaneous immunofluorescence procedure. The upper photomcrograph shows the FITC-labeled, SPLI-containing fibers in the cellular layer of turtle cortex. The lower photomicrograph shows that the same fibers and terminals containing SPLI also are TRITC labeled for the presence of CCK-8-LI. Medial is to the left. 

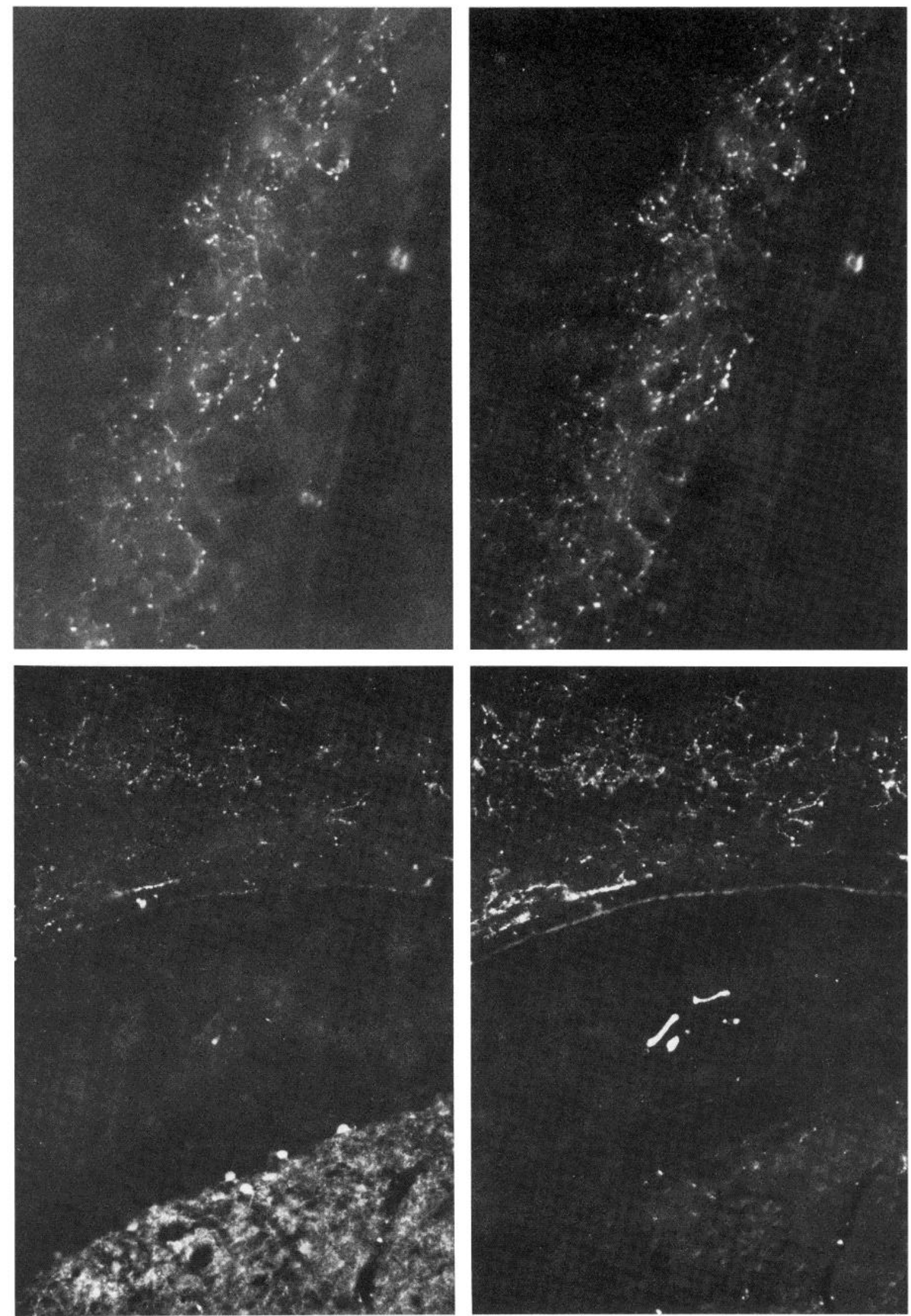

Figure 6. Two pairs of photomicrographs of transverse telencephalic sections that had been processed for the presence of both SP and CCK-8 according to the simultaneous immunofluorescence procedure. The upper pair of photographs shows the FITC-labeled SPLI-containing fibers (to the left) and the TRITC-labeled CCK-8-containing fibers (to the right) in the same field of view of a portion of the CDM. Medial is to the left. Note that all SPLI-containing fibers are also labeled for the presence of CCK-8-LI. In the field of view shown in the lower pair of photomicrographs (taken at a lower power than the upper), the lateral ventricle is evident in the middle of the photomicrograph. CD is evident above the lateral ventricle, and the paleostriatum augmentatum (comparable to the striatum of mammalian basal ganglia) is evident below the ventricle. In the lower left photomicrograph, FITC-labeled SPLI-containing fibers are present in the cellular layer of cortex along the upper edge of the photomicrograph. Along the lower edge of the photomicrograph, several SPLIcontaining neurons and a field of SPLI-containing fibers that are very intensely labeled for SP are evident in the paleostriatum augmentatum. In the lower right photomicrograph, the SPLI-containing fibers of the cortex can be seen also to be TRITC labeled for CCK-8, but the SPLI-containing neurons and fibers of the paleostriatum augmentatum are not TRITC labeled. Medial is to the left in both lower photomicrographs. 

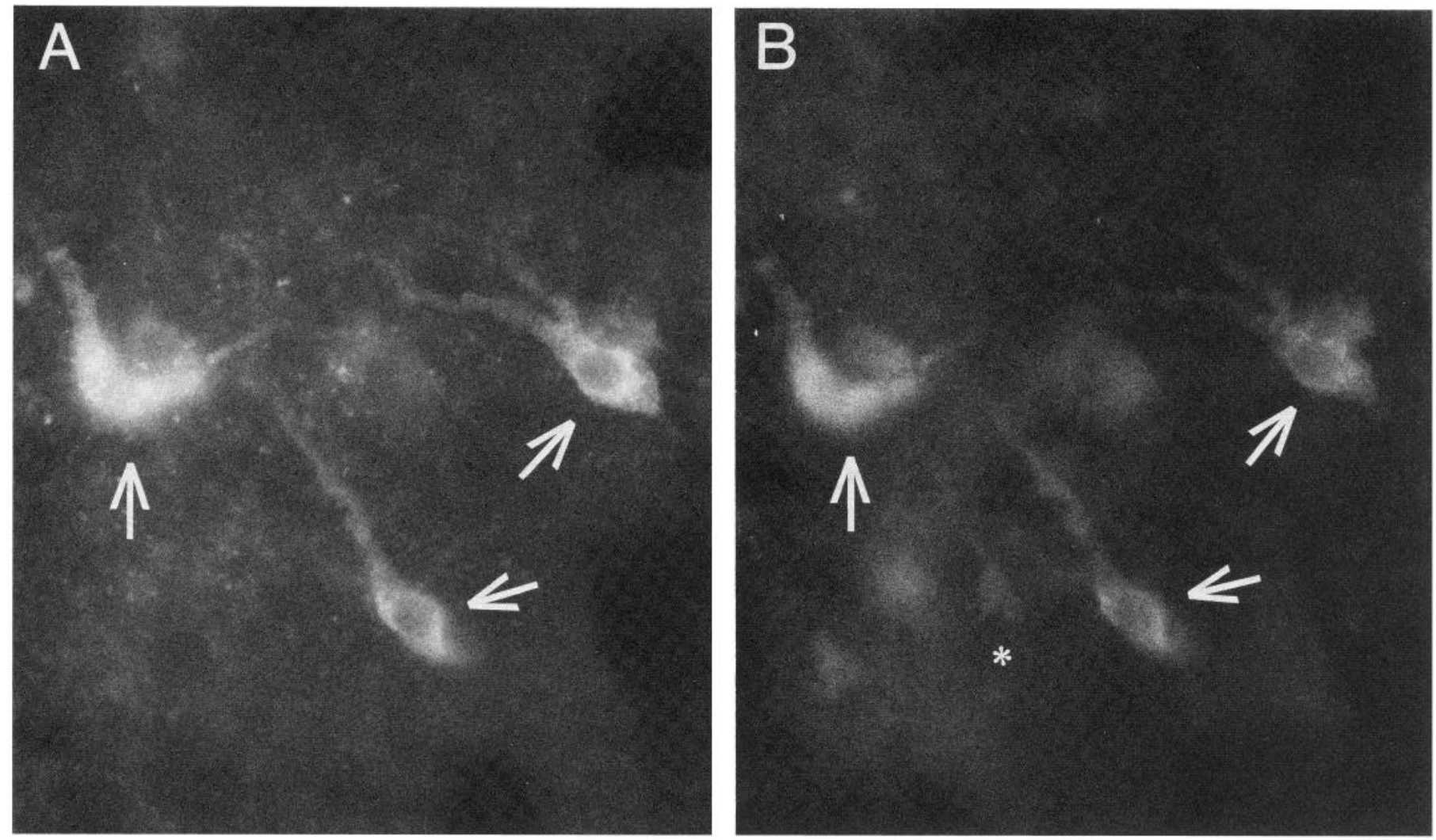

Figure 7. Pair of photomicrographs of a transverse section through the supramammilary region of a turtle that had been processed for the presence of both SP and CCK-8 according to the simultaneous immunofluorescence procedure. The photomicrograph in $A$ shows several FITC-labeled SPLI-containing neurons, and the photomicrograph in B shows that several of the SPLI-containing neurons (arrows) are also TRITC labeled for the presence of CCK-8-LI. The asterisk in $B$ indicates a CCK-8-LI-containing neuron that was not labeled for SPLI.

synaptic contact, the postsynaptic specialization consisted of a relatively uniform, lightly electron-dense material adherent to the cytoplasmic face of the postsynaptic membrane. The synapses appeared to correspond to the asymmetric type.

Labeled terminals also contained many mitochondria and large dense core vesicles (LDCVs). All organelles within labeled terminals were coated with an electron-dense material that was assumed to be peroxidase reaction product. The heavy coat of labeling around these organelles was the basis of the increased electron density of the labeled terminals. In addition, many (but not all) of the LDCVs in the labeled terminals contained a conspicuously dense labeling. These labeled LDCVs were assumed to contain SPLI or CCK-8-LI (depending on the antibody used to process the tissue). Both labeled and unlabeled dense core vesicles were found throughout the labeled terminals, but most frequently the dense core vesicles were found near mitochondria at some distance from the synaptic membrane. No significant difference in mean diameter was found between the LDCVs labeled for SPLI (1454 nm, SEM = 62.4, $N=7)$ and those labeled for CCK-8-LI $(1211 \mathrm{~nm}, \mathrm{SEM}=48.2, N=11)$. Furthermore, no significant difference in mean diameter was found between the labeled and unlabeled LDCVs (in SP-labeled terminals: $1454 \mathrm{~nm}, \mathrm{SEM}=62.4$ for labeled LDCVs, $N=7$, and $1370 \mathrm{~nm}$, $\mathrm{SEM}=34.0$ for unlabeled LDCVs, $N=17$; in CCK-8-labeled terminals: $1211 \mathrm{~nm}, \mathrm{SEM}=48.2$ for labeled LDCVs, $N=11$, and $1224 \mathrm{~nm}, \mathrm{SEM}=52.2$ for unlabeled LDCVs, $N=10$ ).

Based on the presence of unlabeled LDCVs in labeled terminals, the question arose as to whether the unlabeled LDCVs in SP-labeled terminals contained a CCK-8-like material. Similarly, it seemed possible that the unlabeled LDCVs in the CCK-8-labeled terminals contained an SP-like material. Examination of a large number of SP. labeled terminals and CCK-8-labeled terminals suggested that the labeled LDCVs outnumbered the unlabeled LDCVs in both SP. labeled and CCK-8-labeled terminals. To quantify the percentage of labeled versus unlabeled LDCVs in SP-labeled and CCK-8-labeled terminals, three observers independently (and blindly as to the category to which each labeled terminal belonged) counted the number of labeled and unlabeled LDCVs in 13 SP-labeled terminals and 15 CCK-8-labeled terminals. Only profiles in the measured size range of LDCVs and showing the presence of vesicular membrane were counted as LDCVs. Labeled LDCVs were identified by comparison to unlabeled LDCVs in adjacent unlabeled terminals. The results are presented in Table I. In SP-labeled terminals, $72.2 \%$ of the LDCVs were labeled, whereas $64.0 \%$ of the LDCVs in CCK-8labeled were labeled. These percentages are not signficantly different from one another (at the $5 \%$ level) by a $\chi^{2}$ test $\left(d f=1 ; \chi^{2}=\right.$ 2.573). These results indicated that the SP-like material and the CCK-8-like material must, at least in part, be present in the same LDCVs. To further explore the extent of co-occurrence at the vesicular level, cortical tissue was simultaneously labeled by the PAP method for both SP and CCK-8 (Fig. 11). The number of labeled and unlabeled LDCVs in SP/CCK-8-labeled terminals was determined independently by the same three observers as above. These determinations were done at the same time as the determinations for the SP-labeled terminals and the CCK-8-labeled terminals. Each observer worked blindly in terms of the category to which each labeled terminal belonged, using the same criteria to identify labeled and unlabeled LDCVs as noted previously. If the two peptides are in fact present in the same LDCVs, we expected that there would be no reduction in the percentage of unlabeled LDCVs in the terminals labeled for both peptides. Table I shows the results. In 16 SP/CCK-8-labeled terminals, $64.2 \%$ of the LDCVs were found to be labeled. This percentage is not significantly different (at the $5 \%$ level) from those for the SP-labeled $\left(d f=1 ; \chi^{2}=2.580\right)$ and the CCK-8-labeled terminals $\left(d f=1 ; \chi^{2}=0.0039\right)$. Thus, the SP-like 

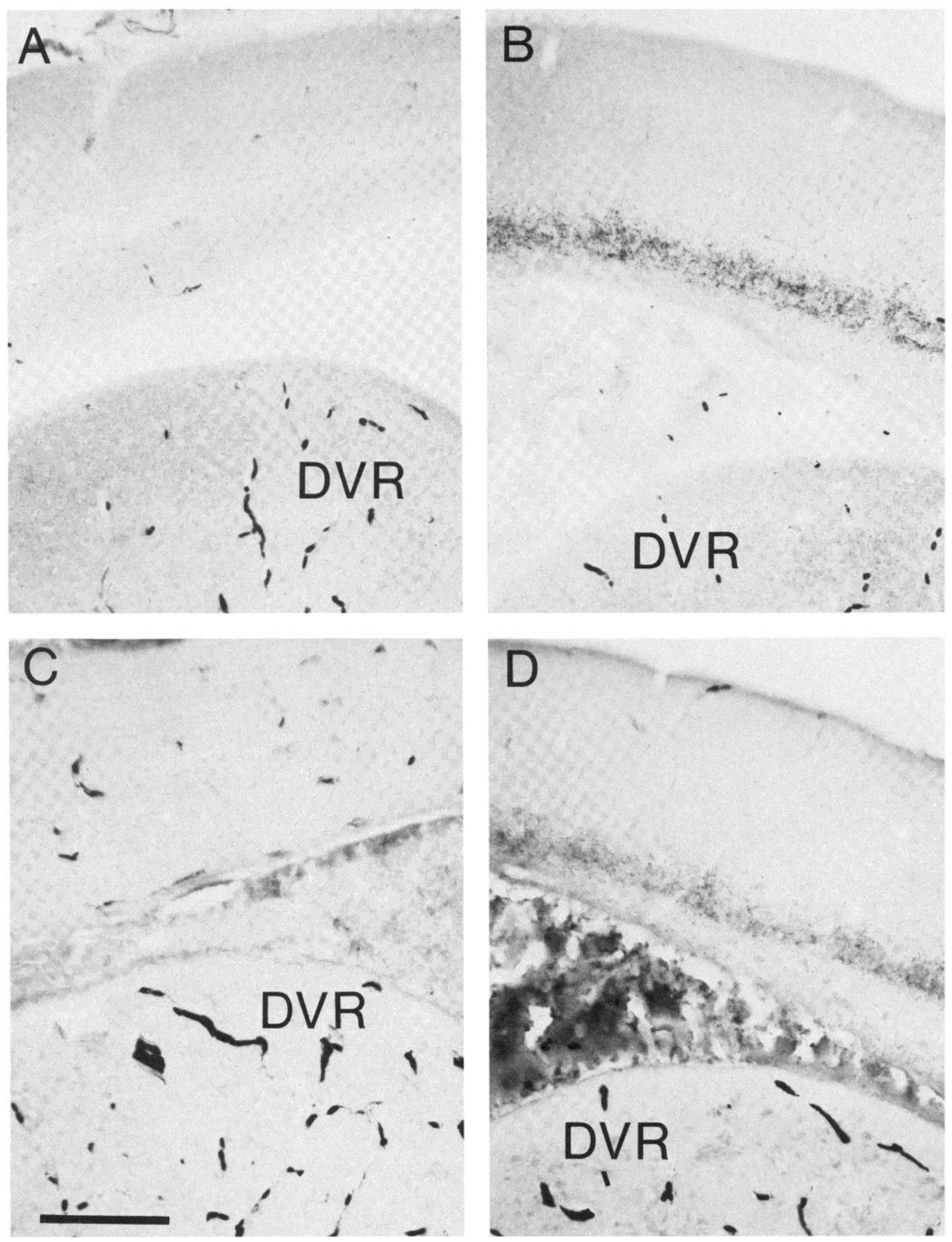

Figure 8. Labeling of fibers in the cortex, using the PAP procedure, following a unilateral knife cut separating CD and PT from the more medial cortices. Normal SP-labeled $(B)$ and CCK-8-LI-labeled $(D)$ fibers are present in the cellular layer of cortex on the non-transected side of the brain. On the transected side of the brain, SP-labeled $(A)$ and CCK-8-labeled $(C)$ fibers are absent from the cellular layer of CD. This result indicates that the SPLI/CCK-8-LI-containing fibers of turtle cortex course from more medial to more lateral cortical regions, originating either from neurons within the more medial cortices or from extracortical neurons that send their axons up the medial wall of the telencephalon. Medial is to the right in $A$ and $C$ and to the left in $B$ and $D$. Scale bar $=$ $200 \mu \mathrm{m}$. 

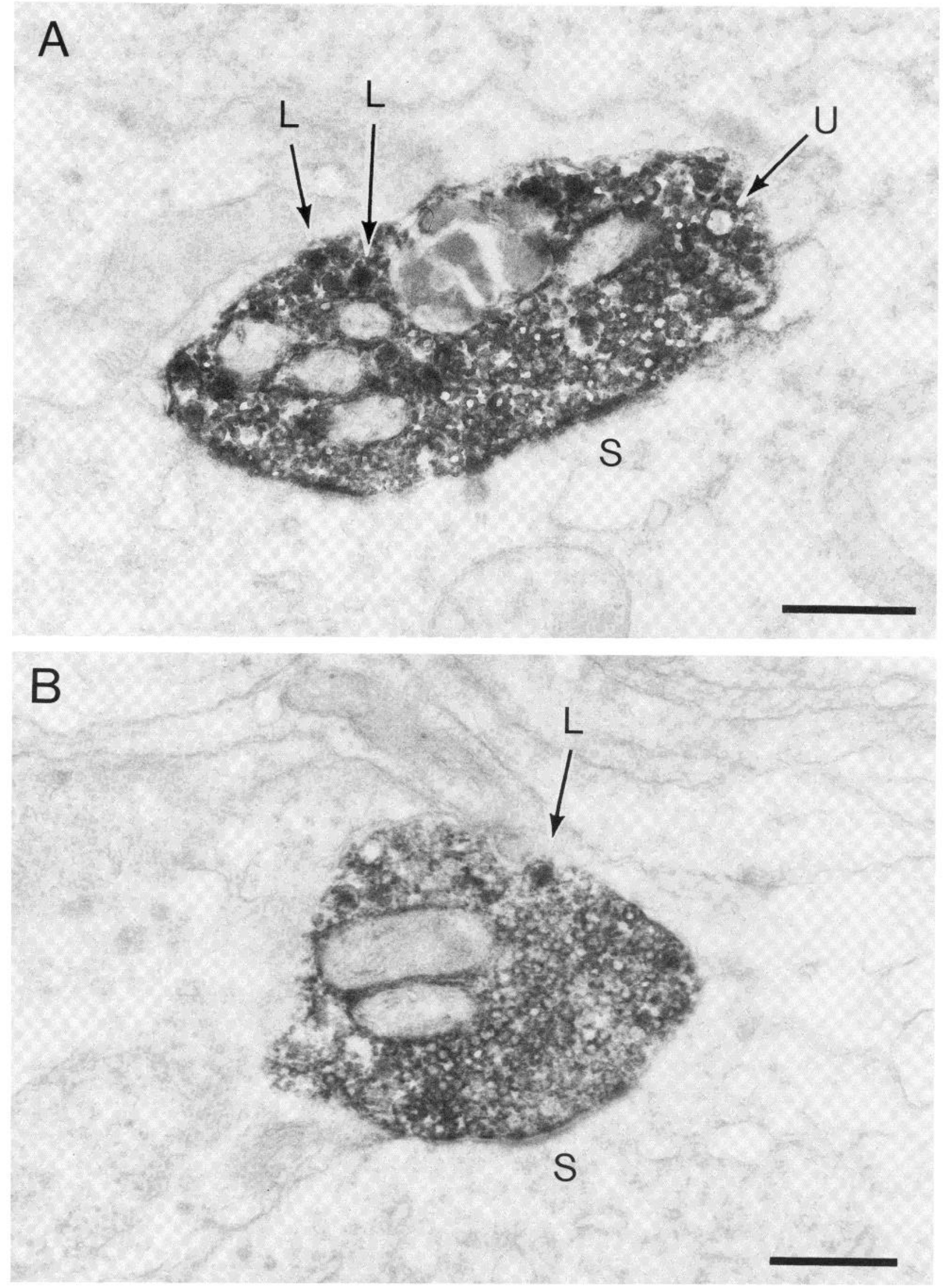

Figure 9. Electron photomicrographs of two SP-labeled terminals in the cellular layer of turtle cortex. Both terminals are making axosomatic synapses that appear to be of the asymmetric type. All organelles within the labeled terminals are heavily coated with DAB reaction product. The labeled terminais contain numerous unlabeled small, clear round synaptic vesicles that are found in high density near the synaptic site $(S)$ and numerous labeled $(L)$ and unlabeled $(U)$ LDCVs. Not all of the LDCVs have been indicated with arrows. Scale bar $=5000 \mathrm{~nm}$. 

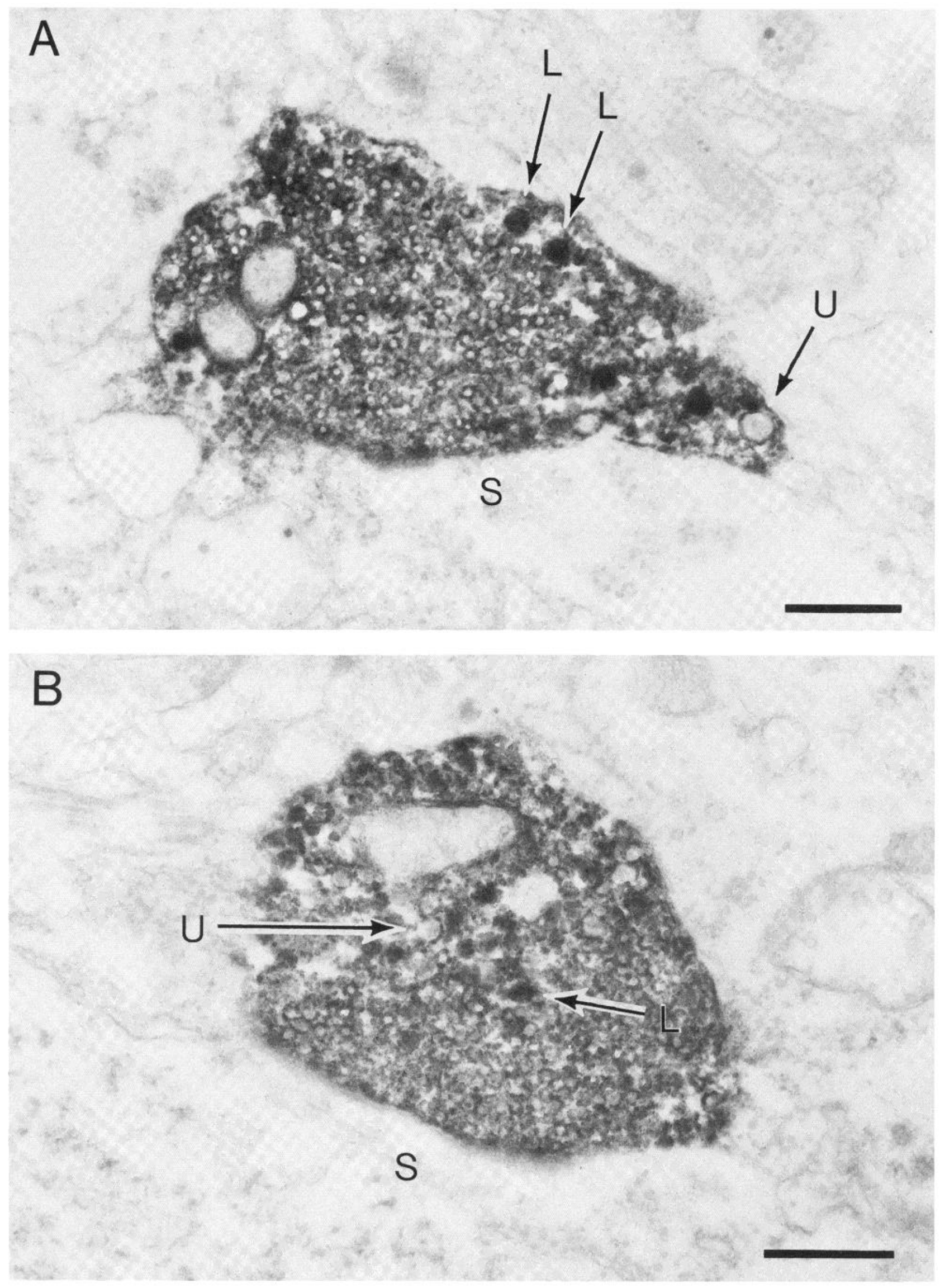

Figure 10. Electron photomicrographs of two CCK-8-labeled terminals in the cellular layer of turtle cortex. As in the case of the SP-labeled terminals shown in Figure 9, the CCK-8-labeled terminals contain numerous unlabeled, small clear round vesicles, labeled LDCVs $(L)$, and unlabeled LDCVs $(U)$. The terminals are making axosomatic synapses $(S)$ that appear to be of the asymmetric type. Not all of the LDCVs in these terminals have been indicated by arrows. Scale bar $=5000 \mathrm{~nm}$. 
TABLE ।

Percentage of total number of LDCVs observed to be labeled or unlabeled in the three different types of labeled terminals studied

\begin{tabular}{lcc}
\hline \multicolumn{1}{c}{ Category of Labeled Terminal } & $\begin{array}{c}\text { Percentage of } \\
\text { Labeled } \\
\text { Vesicles }\end{array}$ & $\begin{array}{c}\text { Percentage of } \\
\text { Unlabeled } \\
\text { Vesicles }\end{array}$ \\
\hline SP-labeled terminals $(74 \pm 6.1)^{a}$ & $72.2 \pm 4.2^{\circ}$ & $27.8 \pm 4.2$ \\
CCK-8-labeled terminals $(116 \pm 8.1)$ & $64.0 \pm 2.4$ & $36.0 \pm 2.4$ \\
SP/CCK-8-labeled terminals $(115 \pm 2.4)$ & $64.2 \pm 3.7$ & $35.8 \pm 3.7$ \\
\hline
\end{tabular}

${ }^{a}$ Numers in parentheses, total number of LCDVs counted for each category of labeled terminal \pm SEM.

${ }^{D}$ All values are the means of individual counts ( \pm SEM) done by the three observers. Criteria used for identification of a profile as an LDCV are described in the text.

material and the CCK-8-like material appear to be present in the same LDCVs in turtle cortex.

Biochemical analysis of immunoreactive peptides. Using exponential gradient elution HPLC, the bulk of the SPLI in turtle cortex elutes in a single profile that is distinct from synthetic SP (see Fig. 12) on the HPLC system used. This peak was also clearly distinct from those for other tachykinins (Harmar, 1984) such as eleodoisin, physalaemin, and $\beta$-neurokinin and consistently distinct from but near those for substance $K$ and kassinin. We have previously found that the concentration of SPLI in turtle cortex is $212 \mathrm{pg} / \mathrm{mg}$ of tissue, as measured by RIA (Reiner et al., 1984). This measurement of SP represents a combined value that includes a measurement of the $\mathrm{SP}$ in the SPLI/CCK-8-LI-containing cortical fibers as well as a measurement of the SP in the SPLI-containing fibers of superficial medial cortex. RIA analysis of the amount of SP in cortical tissue that contains only the SPLI/CCK-8-LI-containing fibers indicates that $0.93 \pm 0.090 \mathrm{pg}$ of SP/ $/ \mu \mathrm{g}$ of cortical tissue protein is found in the SPLI/CCK-8-LI-containing fibers. RIA analysis of turtle cortex for CCK-8 indicated a much lower overall concentration of CCK-8 than of SP in the entire cortex, i.e., $10.4 \pm 4.2 \mathrm{pg}$ of CCK- $8 / \mathrm{mg}$ of tissue $(0.31 \pm 0.11 \mathrm{pg}$ of CCK-8/ $\mu \mathrm{g}$ of cortical tissue protein). Since all cortical CCK-8-LI appears to be present in the SPLI/CCK-8-LI-containing fibers, the cortical concentration of CCK- 8 found specifically in the cellular layer is $0.31 \pm 0.11 \mathrm{pg} / \mu \mathrm{g}$ of cortical protein. Thus, although more SP than CCK 8 appears to be present in the SPLI/ CCK-8-LI-containing fibers, the amounts of SP and CCK-8 in the SPLI/CCK-8-LI-containing fibers are, nonetheless, of the same order of magnitude. The bulk of the CCK-8-LI in turtle cortex coelutes with CCK-8-sulfate in the HPLC system used in the present study (Fig. 12).

\section{Discussion}

The present results indicate that an SP-like material and a CCK-8like material co-occur in an extensive fiber system within the cellular layer of the telencephalic cortex of the turtle. Every fiber and terminal of this system that contains the SP-like material also appears to contain the CCK-8-like material and vice versa. Knife cut studies indicate that this system courses from medial portions of the cortex (CDM and CM) to more lateral portions of the cortex (CD/PT and $\mathrm{CP}$ ), terminating in the perikaryal layer throughout the entire extent of the telencephalic cortical fields. The source of this projection system is not entirely certain at present. Neurons within the more medial portions of the cortex may give rise to this system (Desan, 1981), or neurons outside the cortex may send their axons into the cortex via the medial telencephalic wall. Since the coexistence of SPLI and CCK-8-LI was not evident in neurons of turtle cortex but was evident in many neurons in lateral and supramamillary hypothalamus, a region known to project to the turtle cortex (Desan, 1984), it seems most likely at present that lateral and supramamillary hypothalamus are the source of the SPLI/CCK-8-LI-containing fibers of turtie cortex. The biochemical studies indicate that the CCK-8-like material in these fibers is indistinguishable from CCK-8-sulfate, whereas the SP-like material, although highly similar to SP in terms of immunological reactivity (Reiner et al., 1984), is distinguishable from undecapeptide SP by gradient elution HPLC. The SP-like material found in turtle cortex may represent the SP-like material that is characteristically present in the turtle nervous system. The SP-like material in turtle cortex is indistinguishable by gradient elution HPLC from that found in other portions of the turtle brain, such as the basal ganglia (J. E. Krause and A. Reiner, unpublished observations). The precise structural differences between undecapeptide SP found in mammals and the SP-like material in turtle cortex are presently unknown. The RIA data indicate that the SP-like and CCK-8-like materials are present in molar amounts of the same order of magnitude in the fibers of the cellular layer of turtle cortex, although somewhat more SP-like material than CCK-8-like material appears to be present. At the ultrastructural level, both SPLI and CCK-8-LI are found in LDCVs in terminals that synapse on cell bodies or primary dendrites. Previous electron microscopic immunocytochemical studies have also localized SPLI and CCK-8-LI to LDCVs in other neural systems (Rehfeld et al., 1979; DiFiglia et al. 1982a, b; Erichsen et al., 1982b; Floor et al., 1982). The synapses of the SPLI/CCK-8-LIcontaining terminals onto cell bodies of turtle cortex appear to be of the asymmetric type. The labeled terminals also contain numerous small, unlabeled, round clear core vesicles that are clustered in high density near synaptic membrane. The presence of these small, uniabeled, round vesicles in the labeled terminals indicates that these terminals use an additional (as of yet unidentified) transmitter substance, i.e., that substance present in the small unlabeled round vesicles. In addition, in both the SP-labeled tissue and the CCK-8labeled tissue, labeled terminals contained a number (approximately $35 \%$ of the total number of LDCVs) of unlabeled LDCVs. We have found that simultaneously staining tissue for both SP and CCK-8 does not result in any demonstrable change in the percentage of unlabeled dense core vesicles in labeled terminals. This result provides suggestive evidence for the inferences that the SP-like material and the CCK-8-like material must be present in the same LDCVs and that an additional neuropeptide (or neuropeptides) may be present in these SPLI/CCK-8-LI-containing terminals. This hypothesized additional neuropeptide is presumably contained within the LDCVs that do not label for either SP or CCK-8. Preliminary results indicate that immunohistochemically detectable levels of a VIP-like substance are present in the SPLI/CCK-8-LI-containing fiber system of $\mathrm{CM}$ and CDM of turtle telencephalon (A. Reiner, unpublishcd observations). Consistent with the possibility that the SPLI/CCK-8LI-containing fibers of turtle cortex originate from lateral and supramamillary hypothalamus, VIP-like immunoreactivity is present in numerous neurons of this hypothalamic field in turtles (A. Reiner, unpublished observation).

The function of the SP/CCK-8-containing fiber system of turtle cortex is unknown. Axosomatic terminals making asymmetric synapses in the cell body layer of $C D$ in turtle have been observed previously (Ebner and Colonnier, 1975). These authors noted, however, that the terminals making asymmetric synapses in the cell layer of turtle cortex are considerably outnumbered by terminals containing small flattened vesicles and making symmetric synapses. Smith et al. (1980) have proposed that the predominant input onto the soma of neurons of the cortical cellular layer is inhibitory and arises from stellate cells of the cortical molecular layer. The SPLI/CCK-8LI-containing terminals of the present study may represent the terminals containing round vesicles and making asymmetric synapses described by Ebner and Colonnier (1975). Neurons of the cortical cellular layer also receive excitatory thalamic inputs onto their dendrites in the molecular layer (Ebner and Colonnier, 1978). Thus, the SP/CCK-8-containing fiber system is not the only system, nor even the most morphologically prominent system, influencing the activity of neurons in the cellular layer of turtle cortex. The relative influences of these different systems on the activity of cortical neurons are presently uncertain.

Previous studies have shown that SP and CCK- 8 also co-occur in 

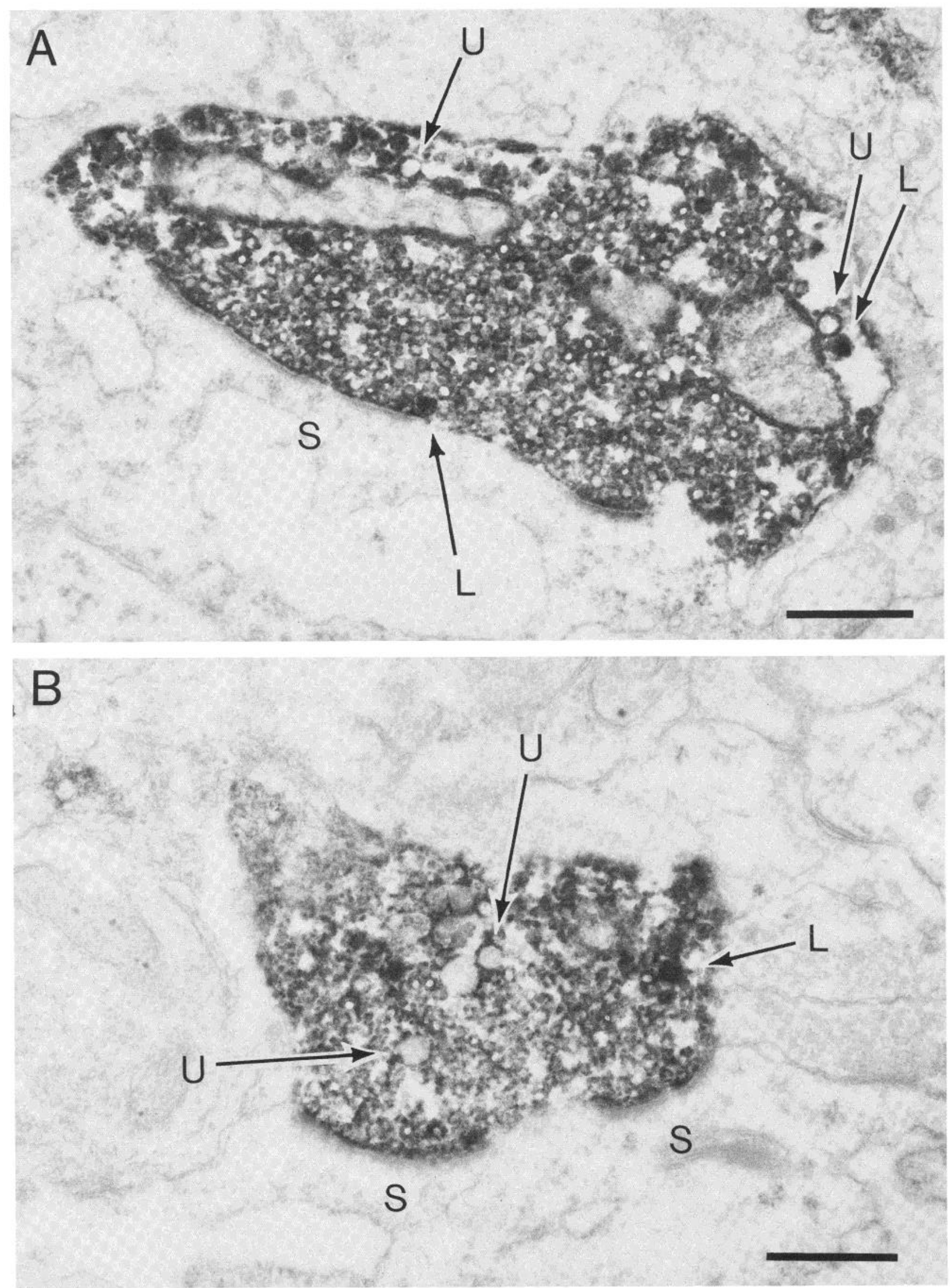

Figure 11. Electron photomicrographs of two terminals in the cellular layer of turtle cortex that have been simultaneously labeled for both SP and CCK-8. The characteristics of these terminals are as described previously for the SP-labeled and the CCK-8-labeled terminals. Of particular interest is the presence of both labeled $(L)$ and unlabeled $(U)$ LDCVs in these SP/CCK-8-labeled terminals. Since these terminals are simultaneously labeled for both SP and CCK8 , the unlabeled LDCVs in these terminals presumably contain neither SPLI nor CCK-8-LI. Quantification of the numbers of labeled and unlabeled LDCVs in SP-labeled, CCK-8-labeled and SP/CCK-8-labeled terminals (see the text) indicates that the numbers of labeled LDCVs are the same in all three types of labeled terminals, thereby implying that the SPLI and CCK-8-LI co-occur in the same LDCVs. Scale bar $=5000 \mathrm{~nm}$. 

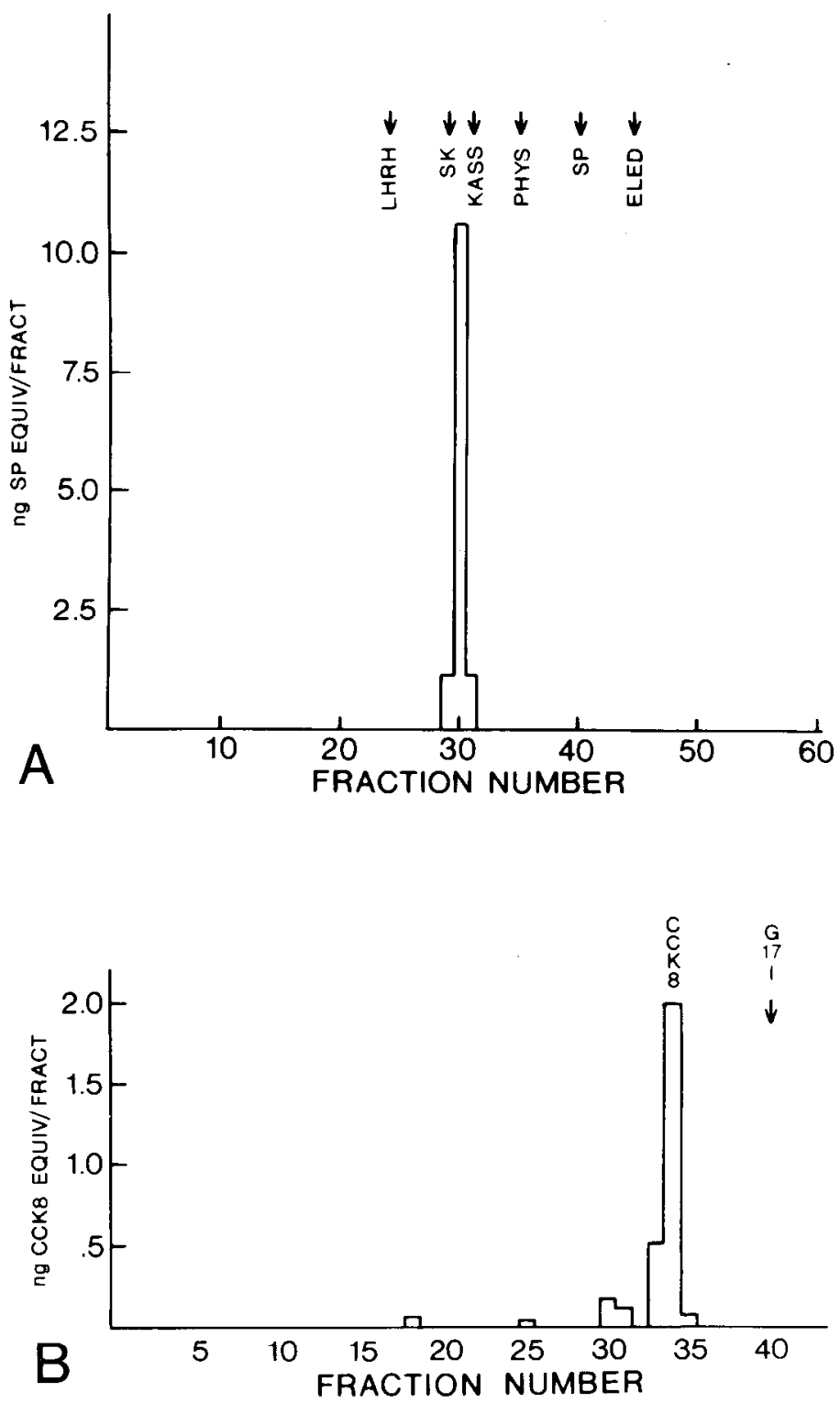

Figure 12. Combined HPI C.RIA of turtle cortical extracts. In $A$, a $2.0 \mathrm{M}$ acid extract of turtle cortical tissue was subjected to exponential gradient HPLC (1 to $30 \%$ acetonitrile) over $50 \mathrm{~min}$ at a flow rate of $1 \mathrm{ml} / \mathrm{min}$ as described under "Materials and Methods." SP RIA was performed on aliquots of the resultant fractions. Bars represent the amount of SPLI and arrows represent the migration of known tachykinin standards. The tachykinin peptide $\beta$-neurokinin is not eluted from the column under these chromatography conditions. Luteinizing hormone-releasing hormone was added to the tissue extract as an internal standard. The SP-like material in turtle cortex was found to elute in this system as a single peak that is distinct from other known tachykinins. In $B$, a $0.1 \mathrm{~N} \mathrm{HCl}$ extract of turtle cortical tissue was subjected to linear gradient elution HPLC (20 to $60 \%$ acetonitrile in the presence of trifluoroacetic acid) over $40 \mathrm{~min}$ at a flow rate of $1 \mathrm{ml} / \mathrm{min}$. CCK8 RIA was performed on aliquots of the resultant fractions. The CCK-8-like material in turtle cortex was found to co-elute as a single peak with authentic CCK-8-sulfate (b). ELED, eledoisin; G17-1, gastrin 17-l; KASS, kassinin; $L H R H$, luteinizing hormone-releasing hormone; PHYS, physalaemin; SK, substance $\mathrm{K}$.

central gray neurons and in dorsal root ganglion neurons of rat (Dalsgaard et al., 1982; Skirboll et al., 1982). The finding that SP and CCK-8 co-occur in three different brain regions and in the members of two different vertebrate classes suggests that SP and CCK-8 may be a common pairing of co-occurrent peptides. Whereas SP/CCK8 co-occurrence is readily apparent in turtle cortex, no data are available on SP/CCK-8 co-occurrence in fibers or perikarya of mammalian cortex. Although high levels of CCK-8 are found in rat cortex, only low levels of SP are found in rat cortex. Higher levels of SP, however, have been found in the cortex of other mammals (e.g., the baboon) (Beach and McGeer, 1983). In the baboon, SP-containing neurons have been reported in at least one of the cortical layers in which CCK-8-containing neurons are abundant, i.e., layer 3. Recently, Gall and Selawski (1983) have demonstrated the existence of an SPLI-containing pathway from the supramamillary hypothalamus to the hippocampus in guinea pig. This finding is of interest since the available data suggest that the most likely source of the SPLI/CCK-8-LI-containing fibers in turtle cortex is from the lateral and supramamillary regions of the turtle hypothalamus. The mammalian data suggest that supramamillary hypothalamus in turtles may project specifically to $\mathrm{CM}$ and $\mathrm{CDM}$, a cortical region traditionally (Johnston, 1915) assumed to be the reptilian equivalent of the mammalian hippocampus. The present data in turtles suggest that fibers from the supramamillary region to the hippocampus in mammals may contain both SPLI and CCK-8-LI, as may inputs to the mammalian neocortex from the lateral hypothalamus (Tigges et al., 1982; Donoghue and Parham, 1983). Consistent with these possibilities, SPLI-containing and CCK-8-LI-containing neurons have been reported in the lateral hypothalamus and supramamillary hypothalamus in mammals (Ljungdahl et al., 1978; Cho et al., 1983).

The preliminary finding that SP, CCK-8 and VIP all are present in the same fibers and terminals in at least a portion of turtle cortex (A. Reiner, unpublished observations) suggests that some of the reported VIP-containing perikarya or fibers of mammalian cortex may also contain CCK-8. Consistent with this possibility, CCK-8 and VIP are both found in bipolar neurons of cortical layers 2 and 3 (MCDonald et al., 1982a, b; Peters et al., 1983). Recently, somatostatincontaining neurons have been identified in the telencephalic cortex of turtle (Bear and Ebner, 1983). Since these neurons appear to be identical in morphology to avian pancreatic polypeptide-like immunoreactivity-containing neurons in turtle cortex (A. Reiner, unpublished observations), it seems possible that somatostatin co-occurs with a pancreatic polypeptide-like substance in neurons of turte cortex, as is also true in mammals (Vincent et al., 1982a, b). The similarities in the peptides found in turtle cortex and in mammalian neocortex may be a reflection of a homologous relationship between turtle cortex and parts of mammalian neocortex, as has been proposed based on several lines of evidence (Hall and Ebner, 1970; Nauta and Karten, 1970; Ebner, 1976). The similarities also suggest that turtles might be suitable subjects for physiological studies exploring the synaptic actions of individual and co-occurrent cortical peptides.

The specific role of SP and CCK-8 in the cortical fiber system of turtle cortex is unknown. In other systems in which neuropeptides and conventional transmitters have been found to co-occur, it has been proposed that the neuropeptides alter the responsiveness of the postsynaptic cell to the conventional transmitter (Nicoll, 1982). In the case of turtle cortex, SP and CCK-8 may act to co-modulate neurotransmission effected by the unidentified transmitter found in the small vesicles clustered near the synaptic membranes. Alternatively, SP, CCK-8, and the conventional transmitter in these terminals may have independent but complementary actions on the postsynaptic cells, as may be the case for some other systems showing peptide-transmitter co-occurrence (Lundberg et al., 1981a, b, 1982). Other instances of the co-occurrence of two neuropeptides with a conventional transmitter have been demonstrated. Neurons of the raphe have been shown to contain TRH, SP, and serotonin (Johansson et al., 1981), and perikarya of the avian nucleus of EdingerWestphal and their terminals in the ciliary ganglion have been shown to contain SP, enkephalin, and acetylcholine (Erichsen et al., 1982a). Since our electron microscopic data suggest that both SP and CCK8 may be present in the same LDCVs in SP/CCK-8-containing terminals of turtle cortex, SP and CCK-8 may be co-released from individual terminals. The possible co-release of SP and CCK-8 leads to the suggestion that SP and CCK-8 must have different actions on the postsynaptic cortical neurons, since it seems unlikely that 
these two peptides would serve redundant functions. In independent studies, SP and CCK-8 have been found to have excitatory effects on cortical neurons (Phillis and Limbacher, 1974; Phillis and Kirkpatrick, 1980; Lamour et al., 1983). Voltage clamp studies of the basis of the excitatory effect of SP on membrane potential have shown that, in cultured spinal neurons, SP acts to decrease a specific voltage-dependent potassium conductance (Nowak and McDonald, 1982). Although this action of SP may not be sufficient to produce postsynaptic action potentials, it can serve to have an overall facilitatory effect on postsynaptic cell firing (Nicoll, 1982). CCK-8 has been found to have excitatory effects on neurons of several different regions of the mammalian nervous system, including the cortex (Phillis and Kirkpatrick, 1980; Dodd and Kelly, 1981; Rogawski, 1982; Lamour et al., 1983). Rogawski (1982) has noted that, as is true of SP, CCK-8 can facilitate cell firing. Although the precise ionic basis of CCK-8's effect on neurons is uncertain, CCK-8 has been found to decrease membrane conductance in cultured spinal cord neurons, and it has been suggested that CCK- 8 may specifically affect potassium conductance in these neurons (Rogawski, 1982). In other systems, however, CCK-8 has been found to excite neurons while increasing their membrane conductance, e.g., pyramidal neurons of the hippocampus (Dodd and Kelly, 1981). The available data, thus, do not provide any unequivocal suggestions as to the nature of the presumptively differential synaptic actions of SP and CCK 8 on cortical neurons in turtles. Both SP and CCK- 8 clearly excite cortical neurons in mammals, but it is unclear whether they act on different ionic mechanisms to effect such excitation.

Regardless of the precise nature of the postsynaptic actions of SP and CCK-8, the apparent vesicular co-occurrence of SP and CCK-8 makes it of interest to determine whether SP and CCK-8 are, under some conditions, differentially synthesized and packaged in the vesicles. Under such circumstances, the ratio of SP to CCK-8 in individual terminals might depend on the paitern of stimulation of the afferent input to the cells of origin of the SPLI/CCK-8-LI-containing terminals. Differences in the ratio of SP release to CCK 8 release might then be important in determining the precise nature of the postsynaptic response. Since SP and CCK -8 have been shown to co-occur in several systems, further understanding of the interaction of SP and CCK-8 in producing responses in postsynaptic cells is of interest. In light of the extensive and apparently complete cooccurrence of these peptides in the presently described fiber system of turtle telencephalic cortex, and in light of the utility of the turtle telencephalon as an electrophysiological preparation (Waldow et al., 1981; Connors et al., 1983), turtles may provide a useful model system to explore SP/CCK-8 interactions in influencing postsynaptic target cells.

\section{References}

Adams, P. R., and D. A. Brown (1980) A luteinizing hormone-releasing factor and muscarinic agonists act on the same voltage-sensitive $\mathrm{K}^{+}$current in bullfrog sympathetic neurones. Br. J. Pharmacol. 68: 353-355.

Beach, T. G. and E. G. McGeer (1983) Neocortical substance P ncurons in the baboon: An immunohistochemical finding. Neurosci. Lett. 41: 265270

Bear, M. F., and F. F. Ebner (1983) Somatostatin-like immumoreaclivily in the forebrain of Pseudemys turtles. Neuroscience 9: 297-307.

Beinfeld, M. C. (1981) An HPLC and RIA analysis of the cholecystokinin peptides in the rat brain. Neuropeptides 1: 203-209.

Beinfeld, M. C., K. K. Meyer, R. L. Eskay, R. T. Jensen, and M. J. Brownstein (1981) The distribution of cholecystokinin immunoreactivity in the central nervous system of the rat as determined by radioimmunoassay. Brain Res. 212: $51-57$

Beinfeld, M. C., J. R. Trubatch, and M. J. Brownstein (1983) Cholecystokinin peptides in the brain and pituitary of the bulltrog Rana catesbiana: Distribution and characterization. Brain Res. 268: 192-196.

Brauth, S. E., A. Reiner, C. A. Kitt, and H. J. Karten (1983) The substance $P$.containing striato-tegmental path in reptiles: An immunohistochemical study. J. Comp. Neurol. 219: 305-327.

Bruce, L. L., and A. B. Butler (1984) Telencephalic connections in lizards. I. Projections to cortex. J. Comp. Neurol. 229: 585-601.
Chan-Palay, V. (1979) Combined immunocytochemistry and autoradiography after in vivo injections of monoclonal antibody to substance $P$ and ${ }^{3} \mathrm{H}$. serotonin: Co-existence of two putative transmitters in single raphe cells and fiber plexuses. Anat. Embryol. 156: 241-254.

Chan-Palay, V., G. Jonsson, and S. L. Palay (1978) Serotonin and substance $P$ co-exist in neurons of the rat's central nervous system. Proc. Natl. Acad. Sci. U. S. A. 75: 1582-1586.

Cho, H. J., Y. Shiotani, S. Shiosaka, S. Inagaki, Y. Kubota, H. Kiyama, K. Umegaki, K. Tateishi, E. Hashimura, T. Hamaoka, and M. Tohyama (1983) Ontogeny of cholecystokinin-8-containing neuron system of the rat: An immunohistochemical analysis. I. Forebrain and upper brainstem. J. Comp. Neurol. 218: 25-41.

Coons, A. H. (1958) Fluorescent antibody methods. In: General Cytochemical Methods, J. F. Danielli, ed., pp. 399-422 Academic Press, Inc., New York.

Connors, B. W., A. R. Kriegstein, and B. R. Ranson (1983) Cellular physiology of the turtle cortex. Soc. Neurosci. Abstr. 9: 679.

Cuello, A. C., G. Galfre, and C. Milstein (1979) Detection of substance P in the central nervous system by a monoclonal antibody. Proc. Natl. Acad. Sci. U. S. A. 76: 3532-3536.

Dalsgaard, C. J., S. R. Vincent, T. Hokfelt, J. M. Lundberg, A. Dahlstrom, M. Schullzberg, G. J. Dockray, and A. C. Cuello (1982) Co-existence of cholecystokinin- and substance P-like peptides in neurons of the dorsal root ganglia of the rat. Neurosci. Lett. 33: 159-163.

Desan, P. (1981) Connections of cerebral cortex in the turtle (Pseudemys scripta elegans). Soc. Neuroscience Abstr. 7: 85

Desan. P. (1984) The organization of the cerebral cortex in the pond turtie, Pseudemys scripta elegans. Ph.D. dissertation, Harvard University, Cambridge, MA.

DiFiglia, M., N. Aronin, and S. E. Leeman (1982a) Light microscopic and ultrastructural localization of immunoreactive substance $P$ in the dorsal horn of monkey spinal cord. Neuroscience 7: 1127-1139.

DiFiglia, M., N. Aronirn, and S. E. Leeman (1982b) Irnrnunoreactive substance $P$ in the substantia nigra of the monkey: Light and electron microscopic localization. Brain Res. 233: 381-388.

Dodd, J., and J. S. Kelly (1981) The actions of cholecystokinin and related peptides on pyramidal neurons of the mammalian hippocampus. Brain Res. 205: 337-359.

Donoghue, J. P., and C. Parham (1983) Afferent connections of the lateral agranular field of the rat motor cortex. J. Comp. Neurol. 217: 390-404.

Ebner, F. F. (1976) The forebrain of reptiles and mammals. In Evolution of Brain and Behavior in Vertebrates, R. B. Masterton, M. E. Bitterman, C. B. G. Campbell, and N. Hotton, eds., pp. 147-167, John Wiley \& Sons, New York.

Ebner, F. F., and M. Colonnier (1975) Synaptic patterns in the visual cortex of turtle. J. Comp. Neurol. 160: 51-79.

Ebner, F. F., and M. Colonnier (1978) Quantitative studies of synapses in turtle visual cortex. J. Comp. Neurol. 179: 263-276.

Eldred, W. D., C. Zucker, H. J. Karten, and S. Yazulla (1983) Comparison of fixation and penetration enhancement techniques for use in ultrastructural immunocytochemistry. J. Histochem. Cytochem. 31: 285-292.

Erichsen, J. T., A. Reiner, and H. J. Karten (1982a) Co occurrence of substance $P$-like and leu-enkephalin-like immunoreactivities in neurons and fibers of avian nervous system. Nature 295: 407-410.

Erichsen, J. T., H. J. Karten, N. C. Brecha, and W. D. Eldred (1982b) Localization of substance $P$-like and enkephalin-like immunoreactivity within preganglionic terminals of the avian ciliary ganglion: Light and electron microscopy. J. Neurosci. 2: 994-1003.

Floor, E., O. Grad, and S. E. Leeman (1982) Synaptic vesicles containing substance $P$ purified by chromatography on controlled pore glass. Neuroscience 6 : 1647-1655.

Gall, C., and L. Selawski (1983) Supramamillary afferents to guinea pig hippocampus contain substance P-like (SP) immunoreactivity. Soc. Neu rosci. Abstr. 9: 1018.

Grimmelikhuijzen, C. J. P. (1983) Co-existence of neuropeptides in hydra. Neuroscience 9: 837-845.

Hall, W. C., and F. F. Ebner (1970) Thalamotelencephalic projections in the turtle (Pseudemys scripta). J. Comp. Neurol. 140: 101-122.

Harmar, A. J. (1984) Three tachykinins in mammalian brain. Trends Neurosci. 7: $57-60$.

Hokfelt, T., H. Steinbusch, A Verhofstad, G. Nilsson, E. Brodin, B. Pernow, and M. Goldstein (1978) Immunohistochemical evidence of substance P like immunoreactivity in some 5-hydroxytryptamine-containing neurons in the rat central nervous system. Neuroscience 3: 517-538.

Hokfelt, T., J. F. Rehfeld, L. Skirboll, B. Ivemark, M. Goldstein, and M. Markey 
(1980a) Evidence for co-existence of dopamine and CCK in mesolimbic neurons. Nature 285: 476-478

Hokfelt, T., L. Skirboll, J. F. Rehfeld, M. Goldstein, M. Markey, and O. Dann (1980b) A subpopulation of mesencephalic dopamine neurons projecting to limbic areas contains a cholecystokinin-like peptide: Evidence from immunohistochemistry combined with retrograde tracing. Neuroscience 5 2093-2124.

Hokfelt, T., O. Johansson, A. Ljungdahi, J. M. Lundberg, and M. Schultzberg (1980c) Peptidergic neurons. Nature 284: 515-521.

Hunt, S. P., P. C. Emson, R. Gilbert, M. Goldstein, and J. R. Kimmel (1981) Presence of avian pancreatic polypeptide-like immunoreactivity in catecholamine and methionine-enkephalin-containing neurons within the central nervous system. Neurosci. Lett. 21: 125-130.

Jacobowitz, D. M., and J. A. Olschowka (1982) Bovine pancreatic polypep tide-like immunoreactivity in brain and peripheral nervous system: Coexistence with catecholaminergic nerves. Peptides 3: 569-590.

Jan, Y. N., and L. Y. Jan (1983) Co-existence and co-release of cholinergic and peptidergic transmitters in frog sympathetic ganglia. Fed. Proc. 42: 2929-2933.

Jan, Y. N., L. Y. Jan, and S. W. Kuffler (1980) Further evidence for peptidergic transmission in sympathetic ganglia. Proc. Natl. Acad. Sci. U. S. A. 77 5008-5012.

Johansson, O., and J. M. Lundberg (1981) Ultrastructural localization of VIPlike immunoreactivity in large dense-core vesicles of "cholinergic type" nerve terminals in cat exocrine glands. Neuroscience $6: 847-862$.

Johansson, O., T. Hokfelt, B. Pernow, S. L. Jeffcoate, N. White, H. W. M Steinbusch, A. A. J. Verhofstad, P. C. Emson, and E. Spindel (1981) Immunohistochemical support for three putative transmitters in one neuron: Co-existence of 5-hydroytryptamine, substance P. and TRH-like immunoreactivity in medullary neurons projecting to spinal cord. Neuroscience 6 . $1857-1881$

Johnston, J. B. (1915) The cell masses in the forebrain of the turtle, Cistudo carolina. J. Comp. Neurol. 25: 393-468.

Korte, G. E., A. Reiner, and H. J. Karten (1980) Substance P-like immunoreactivity in cerebellar mossy fibers and terminals in the red-eared turtle, Chrysemys scripta elegans. Neuroscience 5: 903-914.

Krause, J. E. A J. Reiner, J. P. Advis, and J. F. McKelvy (1984) In vivo biosynthesis of $\left[{ }^{35} \mathrm{~S}\right]$ and $\left[{ }^{3} \mathrm{H}\right]$ substance $P$ in the striatum of the rat and their axonal transport to the substantia nigra. J. Neuroscience 4: 775-785.

Lamour, Y., P. Dutar, and A. Jobert (1983) Effects of neuropeptides on rat cortical neurons: Laminar distribution and interaction with effect of acetylcholine. Neuroscience 10: 107-117.

Ljungdahl, A., T. Hokfelt, and G. Nilsson (1978) Distribution of substance Plike immunoreactivity in the central nervous system of the rat. I. Cell bodies and nerve terminals. Neuroscience 3: 861-944

Lowry, O. H., N. J. Rosebrough, A. L. Farr, and R. J. Randall (1951) Protein measurement with the Folin phenol reagent. J. Biol. Chem. 193: 265-275

Lundberg. J. M., T. Hokfelt, M. Schultzberg. K. Uvnas-Wallenstein, C. Kohler and S. I. Said (1979) Occurrence of vasoactive intestinal polypeptide (VIP) like immunoreactivity in certain cholinergic neurons of the cat: Evidence from combined immunohistochemistry and acetylcholinesterase staining. Neuroscience 4: 1539-1561.

Lundberg, J. M., A. Anggard, and J. Fahrenkrug (1981a) Complementary role of vasoactive intestinal polypeptide (VIP) and acetylcholine for cat submandibular gland blood flow and secretion. I. VIP release. Acta Physiol. Scand. 113: 317-327.

Lundberg, J. M. A. Anggard, and J. Fahrenkrug (1981b) Complementary role of vasoactive intestinal polypeptide (VIP) and actylcholine for cat submandibular gland blood flow and secretion. II. Effects of cholinergic antagonists and VIP antiserum. Acta Physiol. Scand. 113: 329-336.

Lundberg. J. M., A. Anggard, and J. Fahrenkrug (1982) Complementary role of vasoactive intestinal polypeptide (VIP) and acetylcholine for cat submandibular gland blood flow and secretion. III. Effects of local infusions Acta Physiol. Scand 114: 329-337.

McDonald, J. K., J. G. Parnavelas, A. N. Karamanlidis, G. Rosenquist, and $\mathrm{N}$. Brecha (1982a) The morphology and distribution of peptide-containing neurons in the adult and developing visual cortex of the rat. III. Cholecystokinin. J. Neurocytol. 11: 881-895.

McDonald, J. K., J. G. Parnavelas, A. N. Karamanlidis, and N. Brecha (1982b) The morphology and distribution of peptide-containing neurons in the adult and developing visual cortex of the rat. II. Vasoactive intestinal polypeptide J. Neurocytol. 11: 825-837.

Nauta, W. J. H., and H. J. Karten (1970) A general profile of the vertebrate brain with sidelights on the ancestry of the cerebral cortex. In The
Neurosciences, Second Study Program, G. C. Quarton, T. Melnechuk, and F. O. Schmitt, eds., pp. 7-26, Rockefeller University Press, New York.

Nicoll, R. A. (1982) Neurotransmitters can say more than just "yes" or "no." Trends Neurosci. 5: 369-374

Nowak, L. M., and R. L. McDonald (1982) Substance P: Ionic basis for depolarizing responses of mouse spinal cord neurons in cell cultures. $\mathrm{J}$. Neurosci. 2: 1119-1128.

Oertel, W. H., G. Riethmuller, E. Mugnaini, D. E. Schmechel, A. Weindl, C. Gramsch, and A. Herz (1983) Opioid peptide-like immunoreactivity localized in GABAergic neurons of rat neostriatum and central amygdaloid nucleus. Life Sci. 33: 73-76.

Peters, A., M. Miller, and L. M. Kimerer (1983) Cholecystokinin-like immunoreactive neurons in rat cerebral cortex. Neuroscience 8 : 431-448.

Phillis, J. W., and J. R. Kirkpatrick (1980) The actions of motilin, luteinizing hormone-releasing hormone, cholecystokinin, somatostatin, vasoactive intestinal peptide and other peptides on rat cerebral cortical neurons. Can J. Physiol. Pharmacol. 58: 612-623.

Phillis, J. W., and J. J. Limacher (1974) Excitation of cerebral cortical neurons by various polypeptides. Exp. Neurol. 43: 413-423

Powers, A. S., and A. Reiner (1980) A stereotaxic atlas of the forebrain and midbrain of the eastern painted turtle (Chrysemys picta picta). J. Hirnforsch. 21: 125-159.

Rehfeld, J. F., N. Gotterman, L. -t. Larsson, P. C. Emson, and C. M. Lee (1979) Gastrin and cholecystokinin in the central and peripheral neurons. Fed. Proc. 38: 2325-2329.

Reiner, A., H. J. Karten, and N. C. Brecha (1982) Enkephalin-mediated basal ganglia influences over the optic tectum: Immunohistochemistry of the tectum and the lateral spiriform nucleus in pigeons. J. Comp. Neurol. 208. $37-53$.

Reiner, A., H. J. Karten, and A. R. Solina (1983) Substance P: Localization within paleostriatal-tegmental pathways in the pigeon. Neuroscience 9 : 61-85.

Reiner, A., J. E. Krause, K. T. Keyser, W. D. Eldred, and J. F. McKelvy (1984) The distribution of substance $P$ in the turtie nervous system: $A$ radioimmunoassay and immunohistochemical study. J. Comp. Neurol. 226: 5075

Riss, W., M. Halpern, and F. Scalia (1969) The quest for clues to forebrain evolution-the study of reptiles. Brain Behav. Evol. 2: 1-50.

Rogawski, M. A. (1982) Cholecystokinin octapeptide: Effects on the excitability of cultured spinal neurons. Peptides 3: 545-551.

Skirboll, L., T. Hokfelt, J. Rehfeld, A. C. Cuello, and G. J. Dockray (1982) Co-existence of substance $P$ and cholecystokinin-like immunoreactivity in neurons of the mesencephalic periaqueductal gray. Neurosci. Lett. 28: 35-39.

Smith, L. M., F. F. Ebner, and M. Colonnier (1980) The thalamocortical projection in Pseudemys turtles: A quantitative electron microscopic study. J. Comp. Neurol. 190: 445-461.

Sternberger, L. A. (1979) Immunocytochemistry, Ed. 2, John Wiley \& Sons, New York

Tigges, J., M. Tigges, N. A. Cross, R. L. McBride, W. D. Letbetter, and S. Anschel (1982) Subcortical structures projecting to visual cortical areas in squirrel monkey. J. Comp. Neurol. 209: 29-40.

Tramu, G. A. Pillez, and J. Leonardelli (1978) An efficient method of antibody elution for the successive or simultaneous localization of two antigens by immunocytochemistry. J. Histochem. Cytochem. 26: 322-324.

Vincent, S. R., L. Skirboll, T. Hokfelt, $O$. Johansson, J. M. Lundberg, R. P. Elde, L. Terenius, and J. Kimmel (1982a) Co-existence of somatostatinand avian pancreatic polypeptide (APP)-like immunoreactivity in some forebrain neurons. Neuroscience 7: 439-446.

Vincent, S. R., O. Johansson, T. Hokfelt, B. Meyerson, C. Sachs, R. P. Elde, L. Terenius, and J. Kimmel (1982b) Neuropepide co-existence in human cortical neurones. Nature 298: 65-67.

Waldow, U., M. C. Nowycky, and G. M. Shepherd (1981) Evoked potential and single unit responses to olfactory nerve volleys in the isolated turtle olfactory bulb. Brain Res. 211: 267-283.

Watson, S. J., H. Akil, C. W. Richard, and J. D. Barchas (1978) Evidence for two separate opiate peptide systems. Nature 275: 226-228.

Watson, S. J., H. Akil, W. Fischli, A. Goldstein, E. Zimmerman, G. Nilaver, and T. B. van Wimmersma-Greidanus (1982) Dynorphin and vasopressin: Common localization in magnocellular neurons. Science 216: 85-87

Weller, T. H., and A. H. Coons (1954) Fluorescent antibody studies with agents of varicella and herpes zoster propagated in vitro. Proc. Soc. Exp. Biol. Med. 86: 789-794

Wessendorf, M. W., and R. R. Elde (1985) Characterization of an immunofluorescence technique for the demonstration of co-existing neurotransmitters within nerve fibers and terminals. J. Histochem. Cytochem., in press. 